\title{
Molecular genetic diversity in the Origanum genus: EST-SSR and SRAP marker analyses of the 22 species in eight sections that naturally occur in Turkey
}

\author{
Tülin Taşcıoğlu ${ }^{\mathrm{a}}$, Narin Sadıkoğlu ${ }^{\mathrm{b}}$, Sami Doğanlar ${ }^{\mathrm{a}}$, Anne Frary ${ }^{\mathrm{a}, *}$ \\ a Izmir Institute of Technology, Department of Molecular Biology \& Genetics, Urla, Izmir 35430, Turkey \\ ${ }^{\mathrm{b}}$ Department of Pharmacognosy, Faculty of Pharmacy, Inönü University, Battalgazi, Malatya 44280, Turkey
}

\section{A R T I C L E I N F O}

\section{Keywords:}

Origanum L. taxonomy

Oregano

Origanum vulgare

Origanum onites

Genetic polymorphism

Population structure

\begin{abstract}
A B S T R A C T
Origanum (L.) is a genus of herbaceous perennials with culinary and medicinal uses with many species found in the Mediterranean region. The taxonomic classification of species belonging to this genus has been studied using morphological, biochemical and genetic diversity analyses. In this study, the genetic diversity of 22 Turkish Origanum species (including 24 taxa from eight sections) was examined with 46 herbarium specimens from the Mediterranean, Eastern Anatolian, Central Anatolian, and Black Sea regions of Turkey. Molecular marker data were generated from 25 SRAP primer pairs and six EST-SSR primers which produced 325 alleles. Dendrogram, principal coordinate and population structure analyses revealed the relationships among Origanum sections, species and individuals. Gene flow (PhiPT and $\mathrm{Nm}$ ) was also studied for a deeper understanding of the relationships and hybridization patterns between sections and species. Molecular separation of the Origanums roughly corresponded to the taxonomy that Ietswaart proposed in 1980 but also suggested that hybridization among sections and species may result in convergence and/or divergence of different sections and species.
\end{abstract}

\section{Introduction}

The genus Origanum L. belongs to the Lamiaceae (Labiatae) family and is known by the common names oregano and marjoram. These plants have been used for tens of thousands of years (Tepe et al., 2016) as traditional remedies for diseases such as leukemia, diabetes or flu. Their efficacy lies in their essential oil and phytochemical contents which have been shown to stimulate downstream processes enhancing the immune system. As a result, Origanum species have worldwide value and promising commercial uses. Turkey has high oregano diversity and is one of the most Origanum-rich countries. Indeed, O. onites,"Turkish oregano", is one of the most commonly used species and has a diversified phytochemical content including important terpenoids such as thymol which is commonly used as a fungicide (Tepe et al., 2016). Turkey plays a key role in oregano trade with about 15,000 tonnes of product worth $\$ 60$ million exported in 2014 (Sari and Altunkaya, 2015). In Turkey, many Origanum species are given the same common name, "kekik," thus leading to confusion among diverse types. However, only two species, $O$. onites and $O$. vulgare, are cultivated by farmers. In addition, most of the plants collected from the wild and sold in markets are $O$. minutiflorum, $O$. onites and $O$. vulgare subsp. vulgare
(Gurbuz et al., 2011). Turkish oregano populations fall into eight of the ten Origanum sections found worldwide: Amaracus, Anatolicon, Brevifilamentum, Longitubus, Chilocalyx, Majorana, Origanum, and Prolaticorolla. The world plant checklist records 25 taxa (23 species) and 5 hybrids as the current extent of Turkish Origanum L. genetic resources (World Checklist of Selected Plant Families, 2017; Sadikoglu and Ozhatay, 2015).

Molecular genetic analysis has been used to discriminate different Origanum species and to study diversity within and among these species. For example, (Novak et al., 2008) developed 13 expressed sequence tag single sequence repeat (EST-SSR) markers that were polymorphic for two oregano taxa, O. vulgare and O. majorana. In other work, 52 transferable EST-SSR markers were developed for 12 genera of the Lamiaceae family collected from Antalya, Turkey (Karaca et al., 2013). In more recent work, 30 new simple sequence repeat (SSR) and cleaved amplified polymorphic sequence (CAPS) markers were developed for eight Origanum L. species collected from Antalya, Turkey (Ince et al., 2014). In addition to SSRs, random amplified polymorphic DNA (RAPD) markers were used to study phylogenetic relationships within O. vulgare subsp. hirtum populations and between seven Origanum $\mathrm{L}$. species (Katsiotis et al., 2009). Amplified fragment length

\footnotetext{
* Corresponding author.

E-mail address: annefrary@iyte.edu.tr (A. Frary).
} 
polymorphism (AFLP) markers were also used to examine genetic diversity in 21 populations to evaluate the correlation between genetic structure and river flooding in Northwest Europe (Van Looy et al., 2009). In addition, Marieschi et al. (2010) developed sequence characterized amplified region (SCAR) markers for the estimation of genetic diversity among Origanum L. species and applied them to ten species from Italy, the USA and Germany. Recently, Aboukhalid and colleagues studied 670 Moroccan individuals from a single taxon (Origanum compactum) (Aboukhalid et al., 2017). The individuals were collected from 59 locations and analyzed with 15 SSR markers to evaluate their genetic diversity. Genetic diversity can also be studied with sequencerelated amplified polymorphism (SRAP) markers. SRAP markers allow amplification of open reading frames as the primers have CCGG and AATT in the forward and reverse directions, respectively (Li and Quiros, 2001). An advantage of these markers is their ability to amplify fragments across genera. They are usually dominant markers and are suitable for genome wide genetic diversity studies as was shown in lavender (also in the Lamiaceae family) by Stanev et al. (2016).

In this study, we used 25 SRAP primer combinations and six cross genera EST-SSR markers developed by Novak et al. (2008) for molecular characterization of 24 Origanum L. taxa containing 46 individuals that grow naturally in the Mediterranean, Eastern Anatolian, Central Anatolian, and Black Sea regions of Turkey. This is the first time that genetic diversity has been examined in 24 of the 25 Origanum taxa found in Turkey. It is also the first SRAP and EST-SSR combinationbased molecular analysis of these species. This work provides a costefficient approach for determining taxonomic differences between oregano species which may allow reliable selection of parental genotypes in breeding programs. The following questions were addressed by this study: (i) What is the structure of Turkish Origanum L. populations and the level of genetic diversity in the sampled herbarium material? (ii) Is there any significant gene flow between different Turkish oregano taxa? and (iii) How does molecular genetic differentiation compare with what is known about the origin and taxonomy of oregano species as described by Ietswaart (1980)?

\section{Materials and methods}

\subsection{Plant material}

A herbarium collection (assembled between 2005 and 2014) composed of 46 individuals belonging to 24 taxa (22 species) that grow naturally in Turkey was used as a source of plant material from eight sections (sects.) in the genus Origanum (Fig. 1; Table A1). The 46 accessions included all but one taxon (Origanum brevidens) from these sections. The number of individuals per taxa collected from each province ranged from one to 12 . The most specimens were collected from Antalya involving four sections: Chilocalyx, Brevifilamentum, Majorana, and Amaracus (Fig. 1). The Osmaniye province contributed six specimens from sects. Longitubus, Brevifilamentum, Prolaticorolla, and Origanum. Five accessions (accs.) belonging to sects. Amaracus, Majorana, and Origanum were collected from Mersin province. Three specimens from sects. Brevifilamentum and Origanum were collected from Tunceli. Two individuals each were collected from Isparta, and Artvin while Karaman, Hatay, Adana, and Erzincan provinces provided one specimen each. Thus, specimens were sampled to include the wide distribution and diversification of the Origanum L. taxon in Turkey. All plant materials were obtained from the Herbarium Collection Center, Inonu University, Faculty of Pharmacy, Malatya, Turkey.

\subsection{DNA extraction}

Genomic DNA was isolated from dry tissue using a CTAB protocol (Doyle and Doyle, 1987) in combination with a DNA purification procedure for herbarium samples (Costa and Roberts, 2014). Amount and quality of genomic DNA were determined by SkanIt software for
Multiscan Go 3.2 spectrophotometer (Thermo Scientific) and samples were run on $0.8 \%$ agarose gel, stained with ethidium bromide and visualized under UV light. DNA samples were diluted to $50 \mathrm{ng} / \mu \mathrm{l}$ for polymerase chain reaction (PCR) amplification.

\subsection{SRAP analyses}

A total of 25 SRAP primer combinations (Li and Quiros, 2001) was used to obtain random amplicons (Table A2). PCR reactions were conducted in $25 \mu \mathrm{l}$ final volume containing $1 \times$ Tango buffer (with BSA), $3 \mathrm{mM} \mathrm{MgCl}_{2}, 0.125 \mathrm{mM}$ deoxyribonucleotide triphosphates (dNTPs), 1 U Taq DNA polymerase, 2 pmol forward and reverse primers and $50 \mathrm{ng}$ template DNA. The PCR reaction profile was as follows: initial denaturation step at $94^{\circ} \mathrm{C}$ for $5 \mathrm{~min}$, followed by two stages: first $\left(94^{\circ} \mathrm{C}\right.$ for $1 \mathrm{~min}, 35^{\circ} \mathrm{C}$ for $1 \mathrm{~min}, 72^{\circ} \mathrm{C}$ for $1 \mathrm{~min}$ ) for 5 cycles and then (94 ${ }^{\circ} \mathrm{C}$ for $1 \mathrm{~min}, 50^{\circ} \mathrm{C}$ for $1 \mathrm{~min}, 72^{\circ} \mathrm{C}$ for $1 \mathrm{~min}$ ) for 35 cycles with final elongation at $72{ }^{\circ} \mathrm{C}$ for $10 \mathrm{~min}$. PCR products were separated on $2 \%$ agarose gel electrophoresis (run at a constant $110 \mathrm{~V}$ for $3 \mathrm{~h}$ ) and visualized with the BioRad (Universal Hood II) system after ethidium bromide staining.

\subsection{EST-SSR analyses}

Six EST-SSR markers (OR09, OR12, OR13, OR27, OR32, OR40) were used (Novak et al., 2008) (Table A3). PCR reactions were conducted in $25 \mu \mathrm{l}$ final volume containing $1 \times$ reaction buffer, $3 \mathrm{mM}$ $\mathrm{MgCl}_{2}, 0.125 \mathrm{mM}$ dNTPs, $1 \mathrm{U}$ Taq DNA polymerase, 2 pmol forward and reverse primers and $50 \mathrm{ng}$ template DNA. The PCR reaction profile was as follows: initial denaturation step at $94^{\circ} \mathrm{C}$ for $3 \mathrm{~min}$, followed by 40 cycles $\left(94^{\circ} \mathrm{C}\right.$ for $1 \mathrm{~min}, \mathrm{Tm}\left(61-66^{\circ} \mathrm{C}\right)$ for $1 \mathrm{~min}, 72^{\circ} \mathrm{C}$ for $\left.1 \mathrm{~min}\right)$, the final elongation was at $72^{\circ} \mathrm{C}$ for $10 \mathrm{~min}$. PCR products were separated and visualized as described for SRAP markers.

\subsection{Statistical analyses}

The fragments were scored according to presence " 1 " or absence " 0 " for both SRAP and EST-SSR markers. Missing data were coded as " 9 " for each analysis. Forty-five individuals belonging to seven sections out of eight (except section Longitubus with only one individual; O. amanum, OAM1) were used to determine genetic diversity at the section level with GenAlEx 6.5 plugin (Peakall and Smouse, 2006, 2012). Genetic divergence within and between the 11 taxa containing more than one individual (O. saccatum, OSA; O. husnucan-baseri, OHU; O. leptocladum, OLE; O. rotundifolium, ORO; O. majorana, OMA; O.onites, OON; O. syriacum, OSY; O. vulgare subsp. vulgare, OVVU; O. vulgare subsp. hirtum, OVH; O. vulgare subsp. viridulum, OVVI; and O. laevigatum, OLA) was tested with PhiPT analysis (analogous to $F_{S T}$ analysis) on binary data with the GenAlEx 6.5 plugin. PhiPT values less than 0.15 were assumed to indicate significant gene flow between taxa (Frankham et al., 2002). The analysis was performed with "9999" pairwise permutations with $P$ values accepted below 0.001 . In addition, the number of effective alleles $(\mathrm{Ne})$, Shannon's Index $(I)$, and the mean diversity $(h)$ were calculated on random binary data in the same plugin. Pairwise Nei's genetic distances (NGD) and identities (NGI) were also calculated. Number of migrants per generation $(\mathrm{Nm})$ was calculated among populations in Excel using the formula (Wood and Gardner, 2007):

$N m=0.25 *\left[\left(\frac{1}{\text { PHIPT }}\right)-1\right]$

\subsection{Population structure and dendrogram analyses}

Genetic diversity (GD) values for the 31 markers were calculated with GDdom software (Abuzayed et al., 2016). An unweighted Neighbor Joining (NJ) dendrogram was constructed with DARwin 6.0.8 


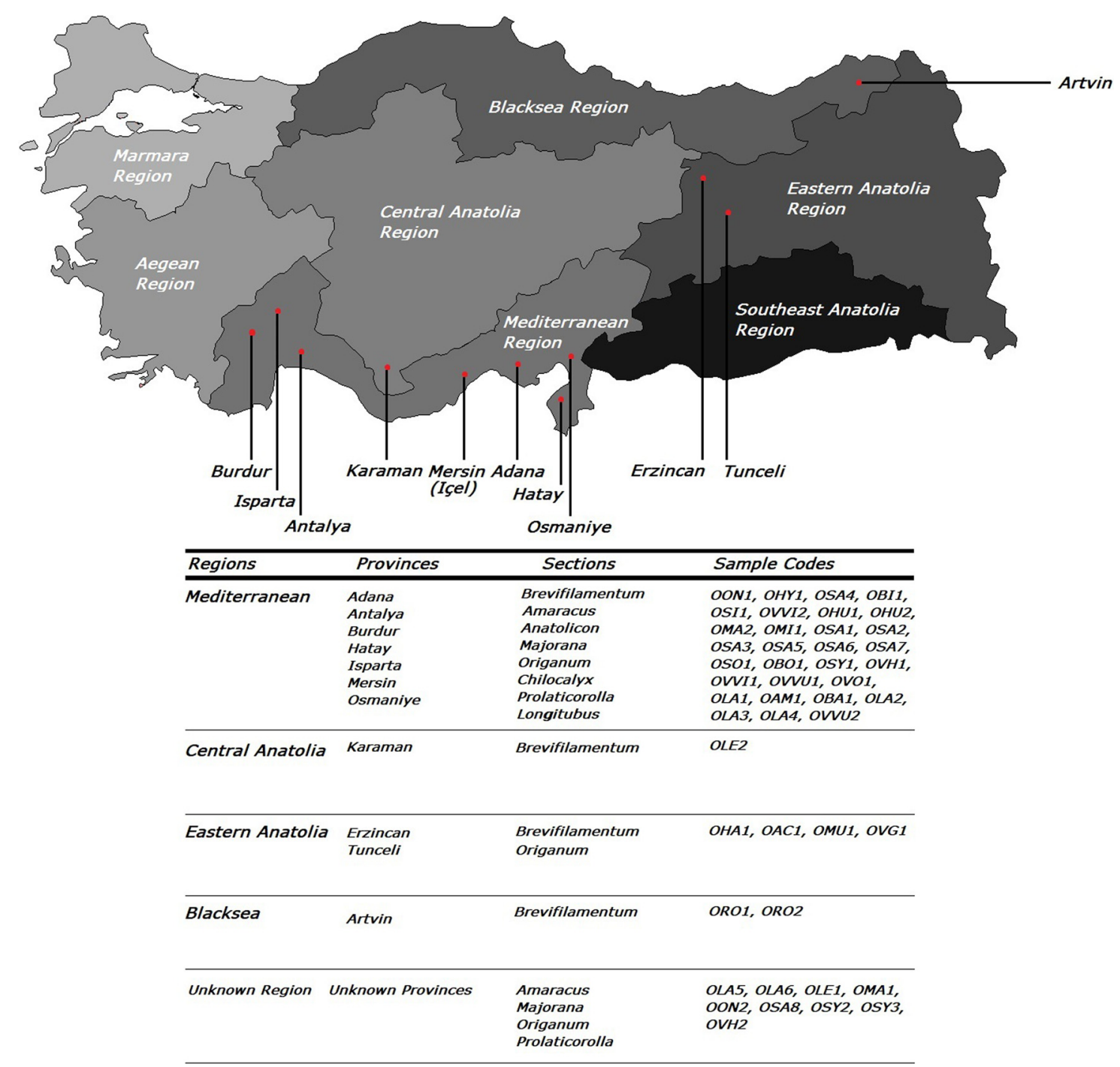

Fig. 1. Collection locations of Origanum L. samples used in this study.

software (Perrier and Jacquemoud-Collet, 2006) using the Jaccard dissimilarity index. Principal Coordinate Analysis (PCoA) was used to produce a graphical display of distances between units on Euclidean planes using DARwin 6.0.8 software and GenAlEx 6.5 plugin (Perrier and Jacquemoud-Collet, 2006; Peakall and Smouse, 2006).

A model-based clustering method was utilized and the structure of the population was determined with STRUCTURE 2.3.4 software (Pritchard et al., 2000) with a Bayesian approach. For an optimal value of subpopulations $(K)$, the $K$ was tested for 1-10 groups and 10 iterations were done for each $K$. The 100,000-initial burn-in replications were followed by 100,000 Markov Chain Monte Carlo (MCMC) replications. The optimal number of $K$ subpopulations was determined using the Structure Harvester website program (Earl and vonHoldt, 2012) after the STRUCTURE run was completed. An identity threshold of 0.70 was used for membership to a given subpopulation since Scutari and Denis assumed that any value between 0.5 and 0.85 yields the same pattern (Scutari and Denis, 2014). Individuals with identity values less than this threshold were assumed to be admixed.

\section{Results}

\subsection{Genetic diversity analyses}

Genetic diversity at the section and species/taxon levels of the accessions was determined using 25 SRAP primer combinations and six EST-SSR markers. 325 polymorphic alleles were obtained. The number of polymorphic alleles per SRAP marker ranged from 3 to 20 with a mean of 12.04 (Table 1). The highest GD value for the SRAP markers was 0.35 which was obtained for primer combination em4-me3. The number of polymorphic alleles per EST-SSR marker ranged from 2 to 6 with a mean of 4 (Table 1). The most polymorphic EST-SSR marker was OR09 with a GD value of 0.49. Despite yielding fewer fragments, ESTSSR markers had higher mean GD (0.36) than SRAP markers $(0.27)$ (Fig. A1). Mean allele frequencies (af) among all polymorphic markers ranged from 0.11 to 0.38 while individual af ranged between 0.02 and 0.96 (Fig. A2).

Within section diversity was high (83\%) with the remaining $17 \%$ of diversity observed among the seven sections as determined by AMOVA analysis. Genetic diversity of the sections ranged from 0.40 to $0.42(h)$. In addition, the NGI indicated that sects. Majorana and Origanum were most similar at the molecular level (0.88) while Majorana and Brevifilamentum were least similar (0.83) (Table 2). Gene flow and $\mathrm{Nm}$ in the seven oregano sections and their pairwise combinations indicated the most gene flow between sects. Anatolicon and Brevifilamentum (Table A4). The least gene flow was observed between sects. Anatolicon and Prolaticorolla.

For the 11 species with more than one individual, the mean $\mathrm{Ne}$ was 1.6, the mean value of $I$ was 0.48 , and $h$ was 0.33 . The highest $I$ was 
Table 1

Average number of polymorphic alleles $(\mathrm{Na})$, allele frequency and genetic diversity (GD) for each marker listed from the lowest to highest value. A dagger $(\dagger)$ indicates type of marker used in this study. SE: Standard error.

\begin{tabular}{|c|c|c|c|c|c|}
\hline Type† & Marker & $\mathrm{Na}$ & Allele Frequency & $\mathrm{GD} \pm \mathrm{SE}$ & Average GD \\
\hline \multirow[t]{25}{*}{ SRAP } & em11-me3 & 11 & 0.14 & $0.14 \pm 0.04$ & \multirow[t]{25}{*}{0.27} \\
\hline & em6-me2 & 3 & 0.38 & $0.18 \pm 0.09$ & \\
\hline & em1-me2 & 19 & 0.18 & $0.20 \pm 0.03$ & \\
\hline & em13-me3 & 8 & 0.13 & $0.21 \pm 0.05$ & \\
\hline & em5-me2 & 19 & 0.16 & $0.22 \pm 0.03$ & \\
\hline & em2-me2 & 11 & 0.11 & $0.24 \pm 0.04$ & \\
\hline & em5-me4 & 19 & 0.15 & $0.25 \pm 0.03$ & \\
\hline & em2-me4 & 8 & 0.26 & $0.26 \pm 0.05$ & \\
\hline & em7-me2 & 13 & 0.24 & $0.26 \pm 0.05$ & \\
\hline & em15-me3 & 7 & 0.23 & $0.26 \pm 0.06$ & \\
\hline & em3-me4 & 14 & 0.21 & $0.27 \pm 0.04$ & \\
\hline & em7-me4 & 16 & 0.24 & $0.27 \pm 0.04$ & \\
\hline & em6-me3 & 20 & 0.21 & $0.29 \pm 0.03$ & \\
\hline & em1-me3 & 16 & 0.18 & $0.29 \pm 0.04$ & \\
\hline & em7-me3 & 5 & 0.2 & $0.29 \pm 0.07$ & \\
\hline & em1-me4 & 11 & 0.23 & $0.30 \pm 0.05$ & \\
\hline & em8-me4 & 9 & 0.24 & $0.30 \pm 0.06$ & \\
\hline & em3-me3 & 13 & 0.25 & $0.31 \pm 0.03$ & \\
\hline & em5-me3 & 10 & 0.27 & $0.31 \pm 0.05$ & \\
\hline & em2-me3 & 14 & 0.2 & $0.32 \pm 0.04$ & \\
\hline & em3-me2 & 7 & 0.19 & $0.32 \pm 0.05$ & \\
\hline & em11-me2 & 10 & 0.28 & $0.33 \pm 0.05$ & \\
\hline & em15-me2 & 7 & 0.21 & $0.33 \pm 0.05$ & \\
\hline & em8-me2 & 15 & 0.28 & $0.34 \pm 0.04$ & \\
\hline & em4-me3 & 16 & 0.3 & $0.35 \pm 0.03$ & \\
\hline \multirow[t]{6}{*}{ EST-SSR } & Or12 & 6 & 0.16 & $0.25 \pm 0.06$ & \multirow[t]{6}{*}{0.36} \\
\hline & Or32 & 4 & 0.27 & $0.33 \pm 0.04$ & \\
\hline & Or40 & 4 & 0.28 & $0.33 \pm 0.07$ & \\
\hline & Or27 & 4 & 0.25 & $0.37 \pm 0.05$ & \\
\hline & Or13 & 4 & 0.31 & $0.40 \pm 0.04$ & \\
\hline & Or09 & 2 & 0.32 & $0.49 \pm 0.00$ & \\
\hline
\end{tabular}

$\Sigma N a=325$.

Definitions are as follows: $\Sigma N a=$ total number of polymorphic alleles.

0.50 for species OHU and OSY. Also, $h$ was highest for the same two species, 0.35. Taxa OLE, OMA, OVVU and OVVI had slightly lower levels of diversity. While, the lowest diversity was seen in the $\mathrm{OVH}$ samples $(I=0.44, h=0.31)$. The mean percentage of polymorphic loci among the 11 Origanum taxa was $75 \%$. The highest percentage of polymorphic loci was $79 \%$ for the OHU population. The number of private bands was 0 for all populations (data not shown).

At the species level, AMOVA analysis indicated that the within population variation was $80 \%$, while among population variation was $20 \%$ (Table 3). The highest NGIs were between OLE and ORO (0.80), and OSA and OMA (0.79) (Table 4). The least gene flow was found between taxa OHU and ORO (0.31) (PhiPT, Table A5). The highest gene flow was 0.04 between the OON and OMA populations (NGD of 0.24). As expected from these results, the highest $\mathrm{Nm}$ value, 6.04, was observed between the OON and OMA populations. The $\mathrm{Nm}$ values were also high between the following taxon pairs: OVVU-OSY (3.27), OVHOVVU (3.07), and OVVI-OVH (3.06).
Table 3

AMOVA results for Turkish Origanum L. species at taxon level.

\begin{tabular}{llllll}
\hline Source & df & SS & MS & Est. Var. & $\%$ \\
\hline Among Pops & 10 & 75.852 & 7.585 & 1.098 & $20 \%$ \\
Within Pops & 22 & 97.451 & 4.430 & 4.430 & $80 \%$ \\
Total & 32 & 173.303 & & 5.528 & $100 \%$
\end{tabular}

Definitions are as follows: $\mathrm{df}=$ degrees of freedom; $\mathrm{SS}=$ sum of squares; MS $=$ mean of squares; Est. Var $=$ estimated variance; $\%=$ percentage of variation.

\subsection{Dendrogram analysis}

Jaccard pairwise dissimilarity indices were calculated among individuals and resulted in a mean dissimilarity of 0.76 with values ranging from 0.30 to 0.90 with a cophenetic $r$ of 0.95 . NJ dendrogram analysis indicated three main clusters: A, B, and C (Fig. 2). Sections Majorana $(\varphi)$, Prolaticorolla $(\lambda)$, and Longitubus $(\delta)$ were distributed throughout cluster A. Individuals belonging to section Origanum $(\gamma)$ were placed mainly in cluster A with one accession in cluster B. All but one of the 10 Amaracus $(\alpha)$ accessions were distributed to cluster B with one accession in cluster A. The two Anatolicon ( $\beta$ ) accs. (O. hypericifolium, OHY1 and O. sipyleum, OSI1) were separately placed in clusters B and C. Section Brevifilamentum ( $\chi$ ) was dispersed throughout all clusters of the dendrogram. All three of the Chilocalyx $(\varepsilon)$ accessions were found in subcluster $\mathrm{C} 1$.

Cluster A was composed of 22 individuals from six sections. All but one (O. vulgare subsp. gracile; OVG1) of the accessions belonging to section Origanum were found in subcluster A1. Among these individuals, two $\mathrm{OVH}$ individuals subclustered within A1. OVVU and OVVI were most closely related to these OVH individuals. OVVU2 was placed with individuals from section Majorana in cluster A1. OON and OSY, species in section Majorana, were also found in cluster A1 with OON1 and OON2 most closely related to the Origanum individuals. OSY1, OSY2, and OSY3 formed their own subcluster within A1. All six Prolaticorolla individuals (OLA) were found in cluster A2. Cluster A3 had an interesting distribution of single individuals belong to Majorana (OMA1 and OMA2), Brevifilamentum (OLE1), Longitubus (O. amanum; OAM1), and Amaracus (O. boissieri; OBO1).

Cluster B was composed of 17 individuals from four sections. Subcluster B1 contained all but one individual (O. boissieri, OBO1) of section Amaracus which included the species OSA, OBO and $O$. solymicum (OSO). All but one of the OSA (OSA3) individuals were found in this subcluster. OSA3 was most closely related to OSO1 and OHY1 (section Anatolicon). OHU individuals clustered together in subcluster B2 which also included OLE2 from the same section, Brevifilamentum. Three more Brevifilamentum taxa were found in cluster B3: O. munzurense (OMU), O. acutidens (OAC), and O. haussknechtii (OHA). This cluster also contained OVG1, the only Origanum accession in cluster B.

Cluster $\mathrm{C}$ was composed of seven individuals in three sections. The three individuals [O. vogelii (OVO), O. bilgeri (OBI), and O. minutiflorum (OMI)] from section Chilocalyx were distributed together in subcluster

Table 2

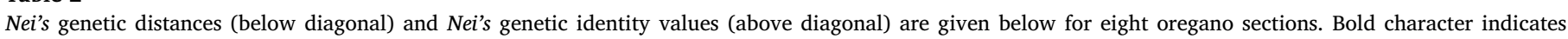

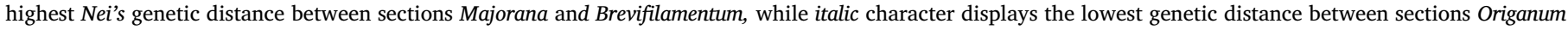
and Majorana.

\begin{tabular}{|c|c|c|c|c|c|c|c|}
\hline Nei's Genetic Distance vs. Nei's Genetic Identity & Amaracus & Anatolicon & Brevifilamentum & Chilocalyx & Majorana & Origanum & Prolaticorolla \\
\hline Amaracus & - & 0.84 & 0.86 & 0.86 & 0.85 & 0.87 & 0.85 \\
\hline Anatolicon & 0.17 & - & 0.86 & 0.84 & 0.84 & 0.86 & 0.84 \\
\hline Brevifilamentum & 0.15 & 0.15 & - & 0.84 & 0.83 & 0.85 & 0.84 \\
\hline Chilocalyx & 0.15 & 0.18 & 0.17 & - & 0.85 & 0.87 & 0.86 \\
\hline Majorana & 0.16 & 0.17 & 0.19 & 0.16 & - & 0.88 & 0.85 \\
\hline Origanum & 0.14 & 0.15 & 0.16 & 0.14 & 0.13 & - & 0.87 \\
\hline Prolaticorolla & 0.16 & 0.18 & 0.17 & 0.15 & 0.17 & 0.14 & - \\
\hline
\end{tabular}


Table 4

Pairwise population matrix with Nei's genetic distance below the diagonal and Nei's genetic identity above the diagonal at taxon level.

\begin{tabular}{|c|c|c|c|c|c|c|c|c|c|c|c|}
\hline & OSA & $\mathrm{OHU}$ & OLE & ORO & OMA & OON & OSY & OVVU & $\mathrm{OVH}$ & OVVI & OLA \\
\hline OSA & - & 0.77 & 0.74 & 0.7 & 0.79 & 0.76 & 0.76 & 0.76 & 0.72 & 0.75 & 0.76 \\
\hline $\mathrm{OHU}$ & 0.27 & - & 0.76 & 0.7 & 0.76 & 0.74 & 0.75 & 0.78 & 0.75 & 0.77 & 0.77 \\
\hline OLE & 0.30 & 0.28 & - & 0.8 & 0.75 & 0.77 & 0.74 & 0.76 & 0.73 & 0.75 & 0.75 \\
\hline ORO & 0.32 & 0.29 & 0.27 & - & 0.76 & 0.76 & 0.73 & 0.73 & 0.73 & 0.75 & 0.73 \\
\hline OMA & 0.24 & 0.27 & 0.29 & 0.3 & - & 0.78 & 0.77 & 0.74 & 0.73 & 0.76 & 0.76 \\
\hline OON & 0.28 & 0.30 & 0.27 & 0.3 & 0.24 & - & 0.74 & 0.75 & 0.70 & 0.73 & 0.74 \\
\hline OSY & 0.27 & 0.29 & 0.30 & 0.3 & 0.26 & 0.30 & - & 0.78 & 0.76 & 0.75 & 0.76 \\
\hline OVVU & 0.28 & 0.24 & 0.27 & 0.3 & 0.30 & 0.28 & 0.25 & - & 0.75 & 0.75 & 0.77 \\
\hline $\mathrm{OVH}$ & 0.33 & 0.29 & 0.32 & 0.3 & 0.31 & 0.36 & 0.28 & 0.29 & - & 0.74 & 0.76 \\
\hline OVVI & 0.28 & 0.26 & 0.28 & 0.3 & 0.28 & 0.32 & 0.29 & 0.29 & 0.30 & - & 0.75 \\
\hline OLA & 0.28 & 0.26 & 0.29 & 0.3 & 0.27 & 0.30 & 0.27 & 0.27 & 0.28 & 0.28 & - \\
\hline
\end{tabular}

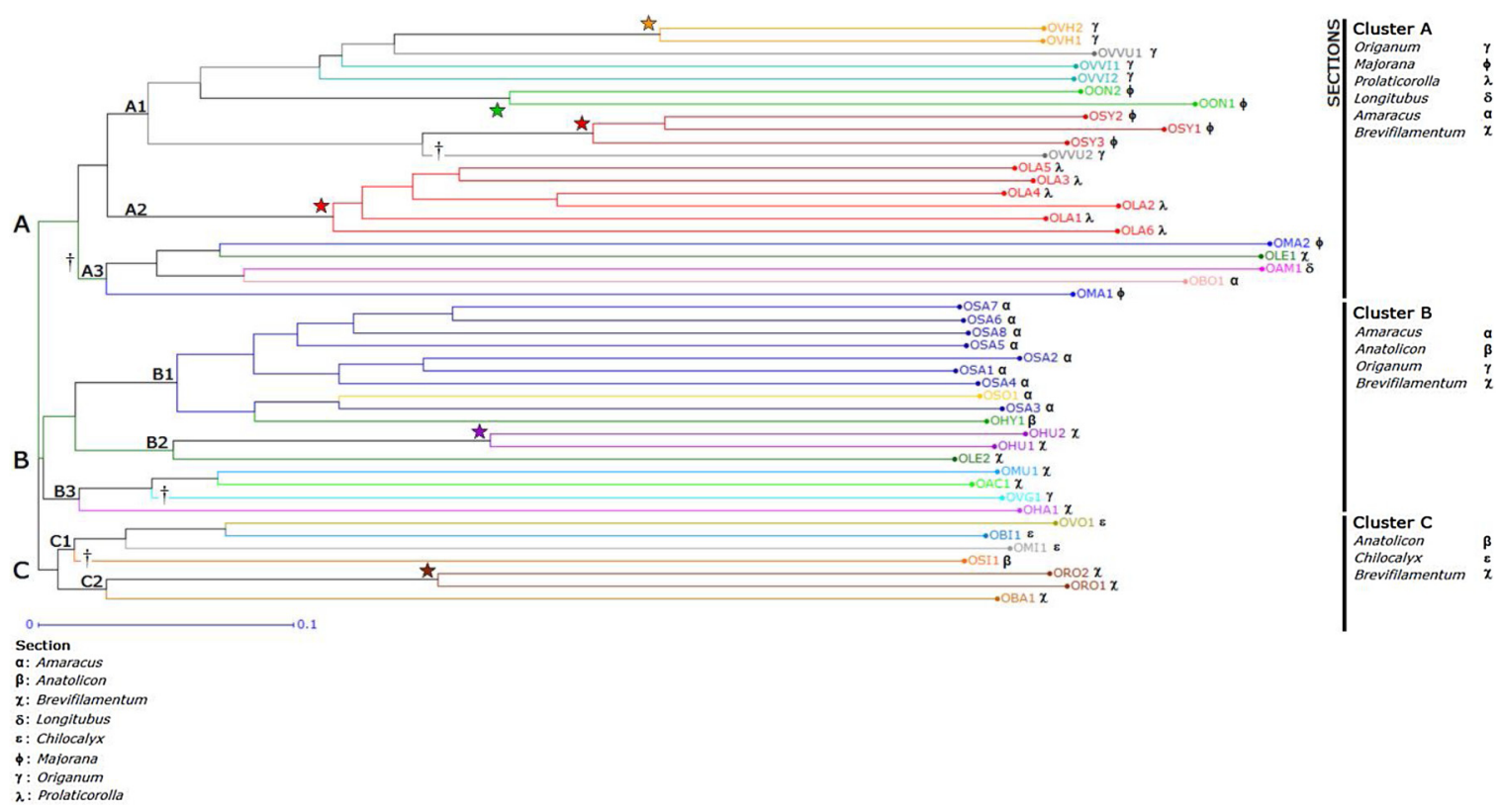

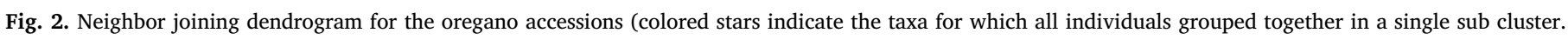
Accessions/clusters which may require re-examination are represented by symbol: $\uparrow$. Sections in each cluster are listed to the right of the dendrogram.

C1. This subcluster also included the OSI individual from section Anatolicon. Subcluster C2 included ORO and the O. bargyli (OBA) individual from the same section, Brevifilamentum.

\subsection{Principle coordinate analysis $(\mathrm{PCoA})$}

The Principle coordinate analysis (PCoA) graph was plotted and the eigen values explained $11.93,8.49$, and $6.52 \%$ of the variance, respectively. The PCoA graph resulted in three major clusters for the 24 taxa (Fig. 3). The distribution of sections was as follows: Prolaticorolla (cluster I); Origanum, Majorana, and Longitubus (cluster II); and Amaracus, Anatolicon, Brevifilamentum, and Chilocalyx (cluster III). Interestingly the individuals OLE1 (Brevifilamentum) and OAM1 (Longitubus) were placed at the intersection of clusters II and III. Cluster I consisted of only OLA individuals which belong to section Prolaticorolla. As indicated, cluster II contained four different sects.: Majorana with all seven individuals from three different taxa (OMA, OON, and OSY); Origanum with its seven individuals from different taxa (OVVU, OVG, $\mathrm{OVH}$, and OVVI); Longitubus with its single OAM individual and Brevifilamentum with one of the ten individuals from the section. The third cluster was composed of four different sects.: Amaracus, Anatolicon, Brevifilamentum, Chilocalyx. Overall, most of the taxa that had more than one individual per population, namely, OLA, OSY, OVVU, OVVI, $\mathrm{OVH}, \mathrm{OON}, \mathrm{OHU}, \mathrm{OSA}$ and ORO were clustered as expected in two dimensions. In contrast, OMA (OMA1 and OMA2) and OLE (OLE1 and
OLE2) individuals were not closely clustered in the plot.

\subsection{Population structure analysis}

The population structure analysis resulted in two possible optimal numbers of subpopulations (Ks) because the most significant delta $K$ $[\Delta(K)]$ values were observed for $K=3$ and $K=8$. An identity threshold value greater than 0.70 was used for classifying individuals into subpopulations or as admixed (Table A6). Because the oregano material encompassed eight sections and $K=8$ gave the highest likelihood value (Fig. A3a), the hypothesis of eight subpopulations was examined first (Fig. 4). The graph for $K=8$ showed that Prolaticorolla formed its own subpopulation (SPVIII). In addition, eight of the 10 Amaracus individuals, specifically those belonging to OSA, fell into a single subpopulation (SPV). Section Brevifilamentum individuals fell into four subpopulations with the ORO and OHU individuals forming exclusive subpopulations (SPIV and VI, respectively). Section Majorana accessions fell almost equally into two subpopulations: SPII and III. Five of the seven accessions from section Origanum were admixed while the remainder (OVH individuals) formed their own subpopulation, SPVII. The individuals from sects. Longitubus and Chilocalyx fell into subpopulations that they shared with other sections (SPI and III) while both Anatolicon accessions were admixed.

Overall, six of the eight (75\%) subpopulations consisted of a single section (Table A6). Of these exclusive subpopulations, SPIV with two 


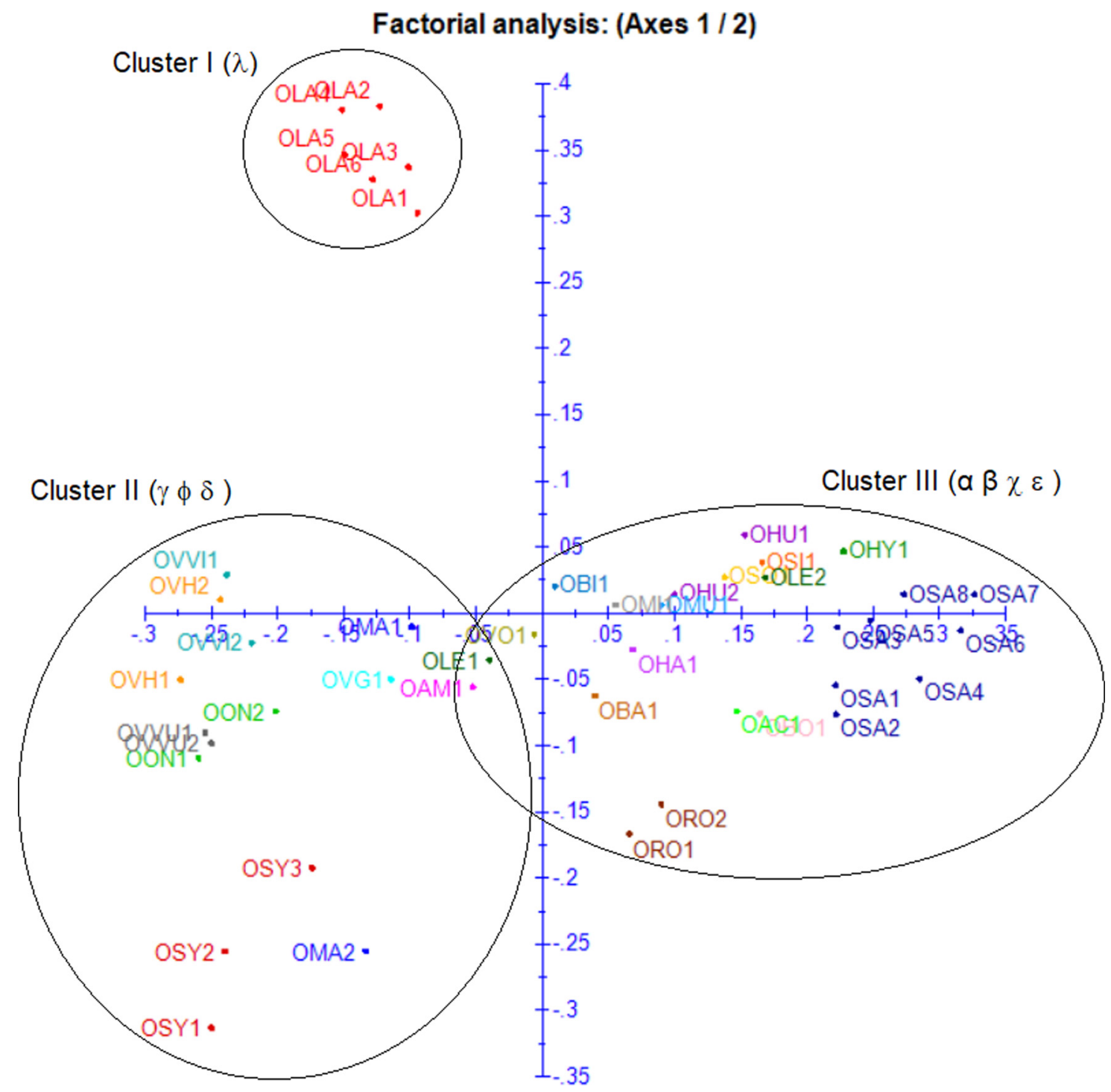

Fig. 3. Principle Coordinate Analysis (PCoA) plot of the oregano material showing three main clusters. Sections are shown in bold with following symbols: $\alpha$ : Amaracus, $\boldsymbol{\beta}$ : Anatolicon, $\chi$ : Brevifilamentum, $\delta$ : Longitubus, $\varepsilon$ : Chilocalyx, $\boldsymbol{\varphi}$ : Majorana, $\gamma$ : Origanum, and $\lambda$ : Prolaticorolla.

ORO accessions had the highest expected heterozygosity $(\mathrm{He})$ value, 0.24 with moderate gene flow $\left(F_{S T}=0.49\right)$ (Table A7). The lowest heterozygosity and gene flow were observed in SPVII which contained only OVH. Overall, SPI with two sects. (Brevifilamentum and Chilocalyx)

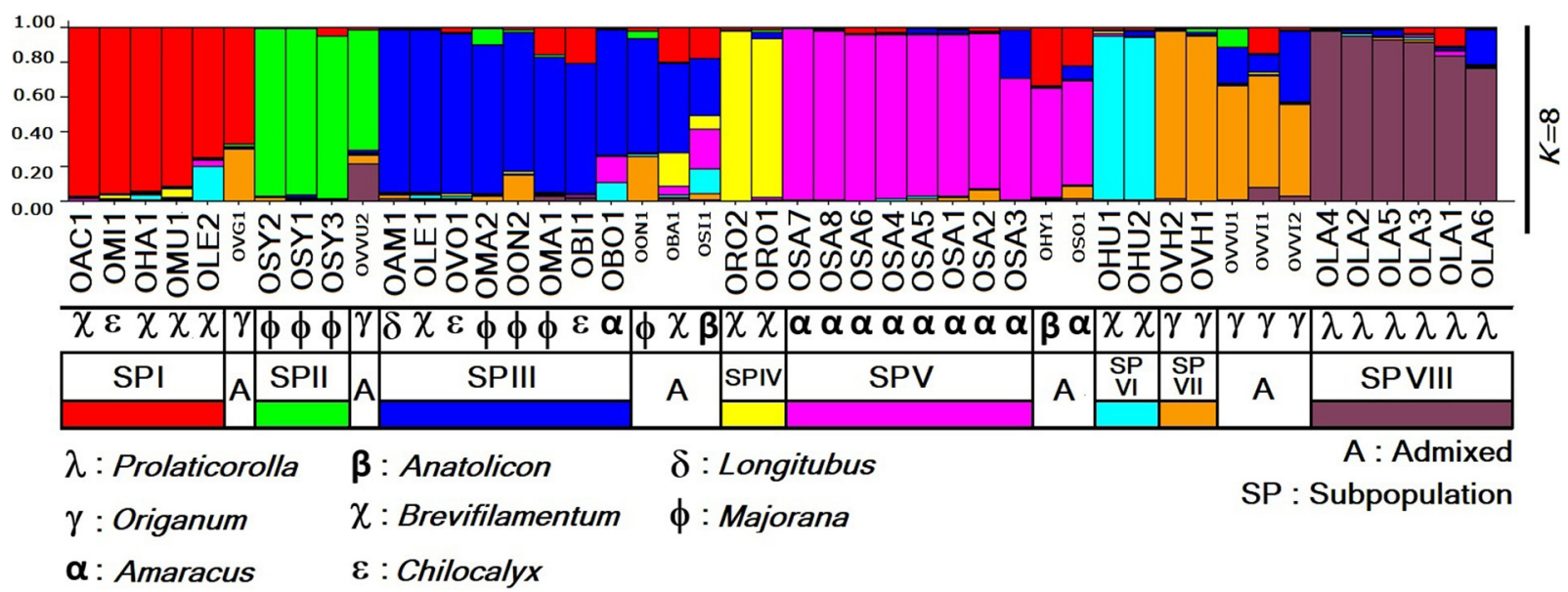

Fig. 4. STRUCTURE graph for eight subpopulations $(K=8)$. The distribution of sections Brevifilamentum, Majorana, Amaracus, Origanum, and Prolaticorolla in separate sub populations is displayed. 
and five different taxa (OAC, OMI, OHA, OMU, OLE) had the highest $\mathrm{He}$ and gene flow, values of 0.34 and 0.02 , respectively. All but one of these species (OLE) was represented by only one accession.

An alternative result from the population structure analysis was that the oregano accessions fell into three subpopulations. This hypothesis was supported by the highest $\Delta(K)$ for all tested values of $K$ (Fig. A3b). Based on these results (Fig. A3c), section Amaracus fell into an exclusive subpopulation, SPII, containing all OSA individuals but excluding OSO1 and OBO1 individuals which were admixed. Accessions from sects. Prolaticorolla, Origanum, Majorana, Longitubus and Brevifilamentum fell into SPIII. The remaining Brevifilamentum individuals were found in SPI (six individuals) and in the admixed group (three accs.). One accession from section Chilocalyx was in SPI and the other two were admixed. The two Anatolicon accessions were admixed. As seen with $K=8$, the SP containing Brevifilamentum and Chilocalyx accessions had the highest gene flow and heterozygosity (Table A7).

\section{Discussion}

\subsection{Origanum L. in Turkey}

Origanum L. is an important medicinal plant with a wealthy essential oil content and special uses in the herbal medicine and food industries. In recent years, there has been a remarkable increase in the number of metabolic and genetic studies of herbs which necessitate that species are correctly identified. The use of morphological characters for taxonomical classification is difficult because these features do not always explain differences between species and their genetic relationships (Lukas et al., 2013). Misclassification confuses both the public's and scientists' knowledge about these plants. For example, Polat and Satil (2012) identified two Origanum species (O. onites and O. vulgare subsp. hirtum) as commonly sold medicinal plants in Balıkesir province in Turkey. Although they correctly indicated that these species belong to the Lamiaceae family, they misclassified them as "thyme;" thus, potentially confusing its genus and common name identifications. Furthermore, there is great difficulty in the identification of various closely related Origanum taxa (Efe, 2013). The complex and indefinite taxonomical classification of Origanum species hinders efforts toward maintaining its sustainability as environmental and human forces change its natural habitat and threaten plant populations. In Turkey, as elsewhere, Origanum specimens that are sold in the market are commonly collected from nature. As a result, harvest and trade, including exportation, are usually uncontrolled. Recently, the Turkish ministry of agriculture has provided incentives to farmers for cultivation of oregano (Gurbuz et al., 2011) which has resulted in increased demand for properly labelled seeds. Thus, many factors contribute to the need for conservation of the fifteen Origanum taxa which are endemic to Turkey.

In this study, the gene pool consisted of 22 Origanum species including 24 taxa growing naturally in Turkey representing eight sections: Amaracus, Anatolicon, Brevifilamentum, Longitubus, Chilocalyx, Majorana, Origanum, and Prolaticorolla. Fifteen of these are endemic species (Table A1). The Origanum vulgare L. accessions included four subspecies: vulgare, gracile, hirtum, and viridulum. These subspecies were included in our study as different taxa. The only endemic taxon that was not included was $\mathrm{O}$. brevidens (Bornmüller) Dinsmore (in section $\mathrm{Bre}$ vifilamentum). This species was only recorded once in 1933 as growing in the Amanos Mountains (Hatay, Turkey) with a limited specimen taken for the herbarium collection which was not sufficient for inclusion in this study (Ietswaart, 1980; Duman et al., 1995; Guzelmansur and Lise, 2013).

\subsection{SRAP and EST-SSR markers in Origanum}

The genetic diversity among Origanum species was investigated in 46 individuals from 24 taxa with SRAP and EST-SSR markers. The SRAP markers yielded 12.04 fragments per primer combination and were highly informative in oregano as is often expected from genetic markers that are based on random or non-sequence specific amplification. Similar results (an average of 13.30 markers) were obtained with RAPD markers in 27 Greek $O$. vulgare subsp. hirtum accessions (Katsiotis et al., 2009).

The EST-SSR markers were also highly polymorphic with an average of four fragments per primer pair. The markers were developed by Novak et al. (2008) who obtained an average of 0.87 fragments in 390 . vulgare and $O$. majorana accessions. This discrepancy in polymorphism is probably due to the fact that the current study examined more accessions from a wider variety of taxa. Some of the same EST-SSR markers were also used to examine $O$. vulgare populations from Tunisia and found to be highly polymorphic with an average of five fragments per marker (Mechergui et al., 2017). Additional EST-SSR markers were developed by Ince et al. (2014). Thirty of these markers were tested on 65 samples from eight Origanum species (Ince et al., 2014) while 15 were surveyed on 670 O. compactum individuals (Aboukhalid et al., 2017). In both studies, the markers yielded a similar number of fragments (one to six) as obtained in our work.

\subsection{Genetic diversity of Turkish Origanum}

Overall genetic diversity of the Turkish Origanum accessions was high with a mean Jaccard dissimilarity index of 0.76 . Ince et al. (2014) also used EST-SSR primers to examine genetic diversity of Turkish Origanum. They analyzed 65 individuals from eight species and obtained an average genetic dissimilarity of 0.46 . Higher diversity was expected in our study given the broad range of material examined: 46 individuals representing 24 of the 25 Origanum taxa. Nearly all Origanum species have identical chromosome numbers $(2 \mathrm{n}=30)$ (Ietswaart, 1980) and the genus can be either self or cross-pollinated with a reported lack of hybridization barriers between species and taxa (Kitiki et al., 1997). Cross-pollination and the resulting high diversity are also aided by the geographical proximity of different Origanum populations (Loveless and Hamrick, 1984). Because the samples were collected from contiguous regions in Turkey, the transfer of pollen or seed from one population into another can result in enhanced gene flow (Loveless and Hamrick, 1984). Furthermore, rivers or streams can also spread seed or pollen of Origanum species as described by Van Looy et al. (2009).

\subsubsection{Section Amaracus}

Ten accessions from three species were sampled from section Amaracus. The average diversity of the section was $0.41(h)$ with highest NGI to section Origanum (0.87). In the dendrogram and PCoA analyses, the section was most closely related to sections Anatolicon and Brevifilamentum. This agreed with the gene flow analysis which indicated that Amaracus had the highest flow and number of migrants with these two sections. In addition, Amaracus and Brevifilamentum species have similar habit and inflorescence structure (Ietswaart, 1980).

NGI and gene flow between the Amaracus species could not be measured because two of the taxa (OBO and OSO) had only one sample. The OSA accessions formed their own cluster with OSO indicating their close genetic relationship which was expected given their membership in the same section as well as the geographical proximity of their collection locations in Burdur and Antalya. Unexpectedly, the OBO1 accession was clustered with a mixed group of individuals from various sections in the dendrogram (cluster A3) and population structure 
analyses. This discrepancy suggests that this particular sample should be re-examined for its morphology and that additional samples of this species should be collected and molecularly characterized. Based on these results, it should be clear if the position of OBO1 is due to its genetic distinctness from the other Amaracus species or if it has been misidentified.

\subsubsection{Section Anatolicon}

Two accessions from two species were sampled from section Anatolicon with an average heterozygosity of 0.41 . Anatolicon had highest genetic identity (0.86) with Origanum and Brevifilamentum. Both Anatolicon accessions were admixed according to the population structure analysis and were not closely related in the dendrogram. Instead, the accessions clustered with individuals from sects. Brevifilamentum, Chilocalyx and Amaracus. In agreement with this result, Anatolicon had high gene flow with these three sections. Indeed, the most migrants observed between sections in the entire study was seen between Anatolicon and Brevifilamentum. Moreover, natural hybrids between Anatolicon species OSI and Brevifilamentum (OBA) have been documented (Ietswaart, 1980). Thus, high rates of cross-pollination could result in the admixed population structure seen in the OHY and OSI samples. Both OHY and OSI are widely distribution in Turkey (Sadikoglu, 2012) which may also contribute to their admixed structure. Anatolicon has also been reported to hybridize with individuals from section Majorana and may hybridize with section Origanum (Ietswaart, 1980). However, especially high gene flow was not observed between these sections in our study. More samples from these species should be collected and analyzed before any conclusions about their genetic structure and relationships with other taxa can be made.

\subsubsection{Section Brevifilamentum}

Ten accessions from seven species were analyzed from section Brevifilamentum. The section had an average diversity of $0.40(h)$ and highest genetic identity with section Origanum (0.85). Individual samples were widely spread in the dendrogram and population structure analysis. The section had the highest gene flow and $\mathrm{Nm}$ with Anatolicon. High gene flow were also observed with Amaracus, Chilocalyx, Origanum and Majorana. The dendrogram and gene flow results indicate the diverse genetic background of Brevifilamentum. These findings are in an agreement with Ietswaart's hypothesis (1980) that many of the species in this section arose through ancient hybridizations when Origanum populations were restricted to mountainous regions due to climate change and a more arid environment. Natural hybrids between Brevifilamentum and Majorana were identified by Ietswaart (1980). The tested Brevifilamentum samples were collected from all regions included in our study which spanned from the Mediterranean to the Black Sea and Eastern Anatolia. Thus, the section is widely dispersed in Turkey and has the opportunity for cross-pollination with many Origanum species.

Of the three Brevifilamentum species that had more than one sample, OHU had the highest $h(0.35)$ followed by OLE (0.34) and ORO (0.32). NGI between these species ranged from 0.75 to 0.76 . The two $\mathrm{OHU}$ samples clustered together in the dendrogram and formed their own subpopulation. These samples were collected in eastern Antalya and were most closely related to OLE2 which was from the adjacent province, Karaman. Interestingly, in the dendrogram, the other OLE accession was placed in the mixed group from various sections (cluster A3) as described previously. The PCoA agreed with this placement as OLE1 was found at the junction between Clusters II and III. Therefore, it would be useful to test other OLE individuals to determine where they are placed in the analyses. The two ORO accessions formed their own subcluster in the dendrogram and PCoA and their own subpopulation in structure analysis. These samples were most closely related to the OBA individual which is also from section Brevifilamentum. The single OAC, OMU and OHA samples clustered in the dendrogram and were in a subpopulation which contained mainly other Brevifilamentum accessions. These three samples (OAC, OMU, OHA) were collected from Tunceli and Erzincan which share a border in Eastern Anatolia. These results suggest cross-pollination between these individuals. However, it is necessary to collect additional samples from these species to get an estimate of their gene flow.

\subsubsection{Section Longitubus}

Only one sample was used from section Longitubus which is comprised of only one species, OAM. The accession clustered with the mixed group of accessions from different sections (Cluster A3) that contained OBO1 (see Section Amaracus) and was found at the junction between Clusters II and III in the PCoA. Natural hybrids between species of Longitubus and Prolaticorolla have been described (Ietswaart, 1980); however, due to a lack of samples, we could not measure gene flow between these sections. Thus, it is evident that additional samples from this species must be collected and analyzed to understand more about the genetic diversity and relationships of this species and section.

\subsubsection{Section Chilocalyx}

Three samples from the three species (OBI, OVO, OMI) in section Chilocalyx were examined and had an $h$ of 0.42 . Chilocalyx had the highest NGI with Origanum (0.87). Indeed, putative hybrids between these two sections have been recorded (Ietswaart, 1980). The Chilocalyx samples formed a distinct cluster in dendrogram analysis and their own subcluster in PCoA. They were most closely associated with the Brevifilamentum accessions, ORO and OBA; and overall, had high gene flow with this section. Significant gene flow was also observed between Chilocalyx, Anatolicon and Majorana. The samples from these sections were collected in the Mediterranean region, thus, facilitating crosspollination.

\subsubsection{Section Majorana}

Seven accessions from the three species in section Majorana were analyzed and had an average genetic diversity of $0.41(h)$. Majorana had the highest NGI with Origanum (0.88). All of the samples were found in the same cluster of the dendrogram. Moreover, OSY and OON accessions formed their own distinct subclusters. The Majorana samples were most closely related to individuals from section Origanum as seen in the dendrogram and PCoA. These results were confirmed by a high gene flow and $\mathrm{Nm}$ between these two sections. Relatively high gene flow was also observed between Majorana, Brevifilamentum and Chilocalyx. Natural hybridization was previously observed between Majorana and sects. Anatolicon, Brevifilamentum, Origanum and Prolaticorolla (Ietswaart, 1980) which indicates that Majorana alleles may migrate even more than observed in our study.

Within Majorana, OSY (0.35) had slightly higher heterozygosity than OMA (0.34) and OON (0.33). High genetic diversity was also identified in the ITS (internal transcribed spacer) region of OSY (Lukas et al., 2013). Genetic identity among the Majorana species ranged from 0.74 to 0.78 . As in the dendrogram analysis, population structure analysis indicated that OSY accessions formed their own subpopulation. Interestingly, these samples had high NGI (0.78) with and were most closely related to one of the two OVVU samples. This relationship was also reflected in a high gene flow between OSY and OVVU. As previously mentioned, the OON samples formed their own dendrogram subcluster. These results are consistent with those of Lukas et al. (2013) who examined the ITS sequences of species in Majorana and found that OON individuals formed a distinct group that did not include OSY or OMA. OON is also unusual in the genus Origanum because its morphology is relatively homogenous and can be easily distinguished from 
other species (Lukas et al., 2013). Highest gene flow for OON was with OMA and OVVI.

The two OMA samples did not cluster most closely with each other but were both found in the mixed cluster A3 and in a subpopulation with multiple sections according to population structure analysis. This situation is mirrored at the morphological level in that OMA has characters which vary in natural populations and are not distinct from OSY (Ietswaart, 1980). OMA is an interesting species because, depending on the expert/genebank, it may or may not include individuals from O. dubium, a morphologically similar taxon (Lukas et al., 2013). Ietswaart (1980) classified O. dubium as a synonym of OMA. However, others who have examined samples at the molecular level argue that $O$. dubium arose by hybridization between OSY and OON (Lukas et al., 2013). Therefore, it is possible that one of our OMA samples could be $O$. dubium, thereby explaining why they did not cluster closely in the dendrogram. OMA had relatively high gene flow with the OLE in Brevifilamentum and OVVI in Origanum. The close relationships and high gene flow between OSY, OON and the $O$. vulgare subspecies may be a result of their geographical proximity as many of the samples were collected in Mersin, Antalya and their surrounding regions.

\subsubsection{Section Origanum}

Seven accessions from four Origanum subspecies were analyzed and found to have an average genetic diversity of $0.42(h)$. In the dendrogram, all but one of the accessions, OVG1 grouped in cluster A1. However, OVG1 did cluster with all the Origanum samples in the PCoA. This disparity could be due to exceptional situation of OVG1 as being the only Origanum accession not collected from the Mediterranean. Instead OVG1 was sampled from Tunceli, a remote region in Eastern Anatolia. This region does not contain natural populations of any of the other $O$. vulgare subspecies. Thus, OVG was isolated from the rest. The Origanum accessions were most closely related to each other and to Majorana accessions. This close relationship with Majorana was also reflected by a high level of gene flow and migrants between the two sections and a high value for NGI (0.88). In addition, both natural and artificial hybrids have been reported for sections Origanum and Majorana (Ietswaart, 1980). Origanum also had high gene flow with Brevifilamentum.

The three subspecies with more than one individual (OVVU, OVH, and OVVI), had similar levels of genetic diversity. The OVH individuals formed their own subpopulation and their own subcluster in dendrogram analysis. OVH also clustered separately from OVVU in the work of Mechergui et al. (2017), which, in common with our work, used the EST-SSRs developed by Novak et al. (2008). Moreover, separate clustering of OVH and OVVU was reported by Katsiotis et al. (2009) using sequence from the ITS1-5.8S-ITS2 region. The remaining Origanum individuals were considered to be admixed in terms of population structure when the number of subpopulations was assumed to be eight, in agreement with Ietswaart's classification (1980). Gene flow was high between OVH, OVVU and OVVI as expected given that they are subspecies and not distinct species. Genetic identity between the subspecies was moderate $(\sim 0.74)$ with some "non-Origanum" taxa more closely related to $O$. vulgare subspecies. For example, OVVU had more genetic identity with OHU and OSY $(\sim 0.78)$ than with OVH and OVVI. These results are in an agreement with the gene flow analysis which indicated high interchange with both Majorana and Brevifilamentum species.

\subsubsection{Section Prolaticorolla}

Section Prolaticorolla contains only one species, O. laevigatum (OLA), and six samples from this species were analyzed in the study. The section had $h$ of 0.41 and highest NGI with Origanum. The section did not have high gene flow with any other section. Average genetic diversity of OLA was 0.33 and this species had relatively high gene flow with only OVVU. All the OLA samples formed a distinct subcluster in the dendrogram and PCoA. This species was most closely related to both Origanum and Majorana accessions. Natural hybrids between Prolaticorolla and Majorana have been described as well as between Prolaticorolla and Longitubus (Ietswaart, 1980). The reason for the seeming genetic distinctness of OLA is unknown given the fact that interspecific hybrids occur and the species is not geographically isolated.

\subsection{Origanum taxonomy}

The origin of the different Origanum sections was proposed by Ietswaart in 1980. According to this hypothesis which assumes 10 sections, sections Amaracus, Majorana, and Origanum were directly descended from species in the ancestral genus Saturejeae (Ietswaart, 1980). Thus, taxa in these sections are the oldest Origanum species which may explain why OON (sect. Majorana) and OVVU (sect. Origanum) are the most numerous and widely distributed oregano species in Turkey, respectively (Sadikoglu, 2012). The prevalence of natural populations of OON may also be explained by its high genetic diversity which has conferred its adaptability to different environments (Ayanoglu et al., 2006). Over time, cross-hybridization among individuals led to gene flow among populations and species. This is evident in the large numbers of migrants that were observed between sections Majorana and Origanum in our study as well as the natural hybrids identified previously (Ietswaart, 1980). Interestingly, despite its ancient origins Amaracus did not exhibit high gene flow with the other two original sections in our work. This may be attributed to the very limited distribution of Amaracus species in Turkey (Sadikoglu, N; personal communication).

Cross-hybridization is common in the genus Origanum and has played a significant role in speciation (Ietswaart, 1980). According to Ietswaart (1980), section Anatolicon arose from many years of hybridization between species in sects. Origanum and Amaracus, and genus Thymus. The admixed population structure of the Anatolicon accessions studied in this work may reflect the diverse origin of this section. This idea is also supported by the high gene flow observed between Anatolicon and Amaracus which could be a remnant of the section's origin or could arise from more recent hybridizations.

According to Ietswaart (1980), section Brevifilamentum arose from hybridizations involving Amaracus and the genus Saturejeae. This hybrid origin may still be evident in the fact that the Brevifilamentum species were the most widely distributed in the dendrogram and population structure analyses. In addition, the results can be attributed to the high gene flow that is ongoing between Brevifilamentum and most of the other sections as well as between some of the Brevifilamentum species. Another key factor is the known endemism of most of these species. For example, $\mathrm{OHU}$ is endemic to only two locations (Sadikoglu, N; personal communication) and formed its own subpopulation in the structure analysis $(K=8)$. Similarly, ORO which has unknown endemism but is considered to be local (Sadikoglu, N; personal communication), also formed its own subpopulation. Both OHU and ORO had very low gene flow with the other species as expected for populations with restricted geographical locations.

Longitubus is hypothesized to be originated from genus Saturejeae and section Amaracus from genus Origanum (Ietswaart, 1980). According to the same source, Longitubus has unique corolla and stamen morphology which distinguish it from the other Origanum sections. In our molecular genetic study, only one individual was included from the section and it was found to cluster with a variety of species from other sections. Thus, it is apparent that morphological differences are not 
necessarily reflected at the molecular level. Of course, additional Longitubus individuals must be examined to learn more about the genetic relationships of this section with the other oregano species.

Chilocalyx arose by hybridizations involving sects. Majorana, Origanum and an unknown genus (Ietswaart, 1980). In our work, Chilocalyx had the highest genetic identity with section Origanum reflecting its origins. In addition, significant gene flow was observed between Chilocalyx and its other progenitor, Majorana. All the Chilocalyx species are endemic and our samples were collected from adjoining Mediterranean locations. Individuals belonging to this section grouped together in our analyses indicating a shared gene pool, however, not enough accessions were studied to examine gene flow and genetic distance.

Prolaticorolla originated from hybridizations involving section Origanum and the genus Saturejeae (Ietswaart, 1980). Indeed, the section had the highest NGI with section Origanum as may be expected from its origin. The section contains only one species which is endemic to the eastern Mediterranean region of Turkey (Sadikoglu, 2012). Perhaps as a result of this endemism, gene flow between this section and the others was the lowest overall and OLA formed its own subpopulation and very distinct clusters in the other analyses.

The population structure analysis of the eight Origanum sections based on molecular genetic data did not have complete concordance with Ietswaart's classification based on morphology (1980). When the results for eight subpopulations are examined, most of the Amaracus ( $80 \%$, all of the OSA acc.), Prolaticorolla (100\%) and Origanum (71\%) individuals fell into distinct subpopulations as expected based on their section assignments. Anatolicon individuals (2 acc.) were admixed and did not fall into any subpopulation which was also true of some Amaracus (1 acc.), Origanum (5 accs.), Brevifilamentum (1 acc.) and Majorana (1 acc.) accessions. The remaining individuals in Brevifilamentum fell into four subpopulations. Two of the subpopulations were exclusive containing only the individuals from one Brevifilamentum species, ORO (2 accs.) and OHU (2 accs.). The other two subpopulations also included species from other sections. These mixed subpopulations contained individuals from Longitubus and Chilocalyx. The members of section Majorana were equally split between two subpopulations, one of which was exclusively OSY ( 3 acc.) from Majorana.

Thus, the main difference between Ietswaart's classification and our subpopulations assignments lies in the occurrence of mixed subpopulations. These were most notable for sects. Brevifilamentum and Majorana. This difference may be simply the result of examining the material at two different levels-morphological versus DNA. Although morphological differences require changes at the DNA level, many more mutations occur in the genome than are apparent from morphology. In addition, the results suggest the possibility that cross-hybridization in these two sections might lead to divergence and speciation. This hypothesis is in agreement with Ietswaart's work (1980) which indicated that hybridization is the main driver of speciation in the genus. A much weaker factor in speciation is geographical isolation (Ietswaart, 1980). This hypothesis is also supported by our finding that endemic species such OHU formed their own subpopulations.

More recently, some researchers have suggested a departure from Ietswaart's classification and have proposed that section Majorana be categorized as its own genus (Kaufmann and Wink, 1994). According to this research which examined $r b c L$ sequence, the genetic distance between $O$. majorana (syn. Majorana hortensis) and $O$. vulgare (subsp. not given) was $1.4 \%$, a value which is typical for inter-genera comparisons. However, our results did not support this hypothesis as the Majorana accessions did not form an outgroup. Ince et al. (2014) obtained similar results with a different set of SSR markers. Moreover, high gene flow (this study) and natural hybridization (Ietswaart, 1980) were observed between section Majorana and other Origanum sections. Thus, our work suggests that Majorana should remain within the genus.

Hybridization is the key factor in Origanum speciation (Ietswaart, 1980 ) and is ongoing in natural populations. Consequently, the species are continuing to evolve. In some cases, this has led to divergence at the molecular and morphological levels while; in other cases, species have become admixed or more similar. This behavior can have different effects on adaptation of the genus to its local environment and result in highly endemic species such as OMU which is only found in one location in Tunceli. It can also result in broadly distributed species like OON. From this perspective, it is clear that the number of sections and species in the genus can change over evolutionary time. In our study, population structure analysis at $K=8$ suggested that some of the species from sections such as Brevifilamentum and Majorana may eventually form their own sections. $K=8$ was selected because it matches Ietswaart's taxonomy and gave the highest likelihood value. However, $K=3$ gave the highest delta $K$ value indicating that the data also fit the hypothesis of three subpopulations. According to this hypothesis, 11 of the accessions were admixed, Amaracus formed its own subpopulation, most of the Brevifilamentum samples formed another subpopulation and the remaining sections were mixed in the third subpopulation. Thus, our results stress that the hybridization behavior of Origanum has complicated its taxonomy and that both morphological and molecular data should be considered when proposing revisions to the genus. In addition, it is evident that more samples from each species must be examined to understand diversity and genetic relationships at the species and section levels in more depth. At the same time such work will aid in conservation efforts by providing methods for species identification. Thus, seeds of known specimens can be collected from nature for tissue culture, greenhouse, field and breeding applications. Such conservation will allow researchers to examine more samples and to devise a robust classification which prevents misidentification and mislabeling of seeds, plants, and culinary and medicinal products.

\section{Data accessibility}

EST-SSR and SRAP marker sequences are available in this article (Tables A2 and A3). All herbarium specimens can be obtained from the Herbarium Collection Center, Inonu University, Faculty of Pharmacy, Malatya, Turkey.

\section{Author contributions}

S.D., A.F., and N.S. designed the study. T.T. conducted both experiments and analyses. N.S. provided herbarium specimens from Inonu University herbarium collection. T.T. and A.F. wrote the manuscript with input from all co-authors.

\section{Funding}

This research did not receive any specific grant from funding agencies in the public, commercial, or not-for-profit sectors.

\section{Acknowledgement}

We are grateful to Inonu University (Faculty of Pharmacy) for providing herbarium specimens.

\section{Appendix A}




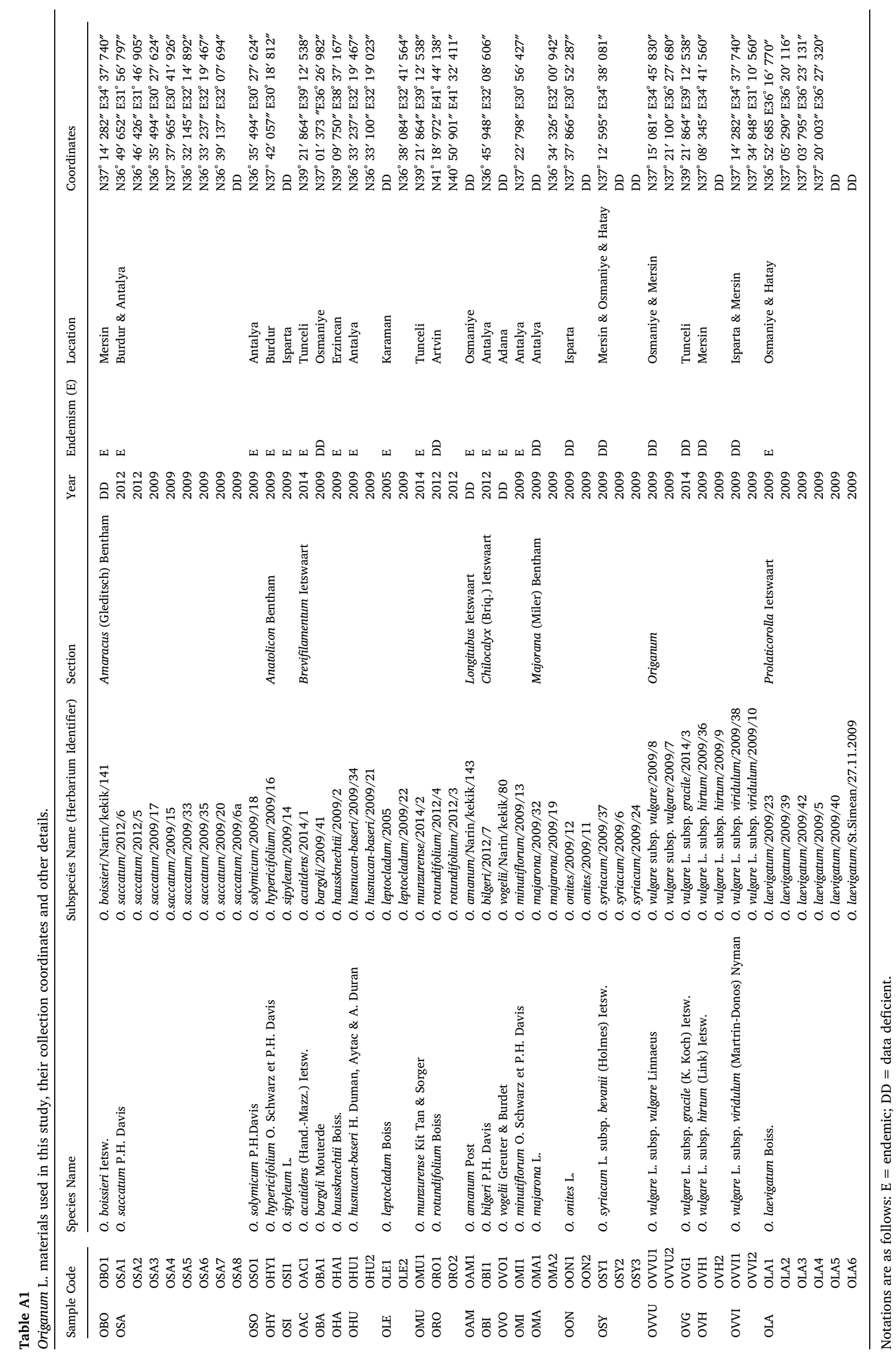


Table A2

SRAP primer combinations and their sequence information.

\begin{tabular}{|c|c|c|c|c|c|}
\hline Primer Type & Pair Code & Forward & Sequence of Forward ( $5^{\prime}$ to $3^{\prime}$ ) & Reverse & Sequence of Reverse ( $5^{\prime}$ to $3^{\prime}$ ) \\
\hline \multirow[t]{25}{*}{ SRAP } & 1 & me2 & TGAGTCCAAACCGGAGC & em1 & GACTGCGTACGAATTAAT \\
\hline & 2 & & & em2 & GACTGCGTACGAATTTGC \\
\hline & 3 & & & em3 & GACTGCGTACGAATTGAC \\
\hline & 4 & & & em5 & GACTGCGTACGAATTAAC \\
\hline & 5 & & & em6 & GACTGCGTACGAATTGCA \\
\hline & 6 & & & em7 & GACTGCGTACGAATTATG \\
\hline & 7 & & & em8 & GACTGCGTACGAATTAGC \\
\hline & 8 & & & em11 & GACTGCGTACGAATTTCG \\
\hline & 9 & & & em15 & GACTGCGTACGAATTCGT \\
\hline & 10 & me3 & TGAGTCCAAACCGGAAT & em1 & GACTGCGTACGAATTAAT \\
\hline & 11 & & & em2 & GACTGCGTACGAATTTGC \\
\hline & 12 & & & em3 & GACTGCGTACGAATTGAC \\
\hline & 13 & & & em4 & GACTGCGTACGAATTTGA \\
\hline & 14 & & & em5 & GACTGCGTACGAATTAAC \\
\hline & 15 & & & em6 & GACTGCGTACGAATTGCA \\
\hline & 16 & & & em7 & GACTGCGTACGAATTATG \\
\hline & 17 & & & em11 & GACTGCGTACGAATTTCG \\
\hline & 18 & & & em13 & GACTGCGTACGAATTGGT \\
\hline & 19 & & & em15 & GACTGCGTACGAATTCGT \\
\hline & 20 & me4 & TGAGTCCAAACCGGACC & em1 & GACTGCGTACGAATTAAT \\
\hline & 21 & & & em2 & GACTGCGTACGAATTTGC \\
\hline & 22 & & & em3 & GACTGCGTACGAATTGAC \\
\hline & 23 & & & em5 & GACTGCGTACGAATTAAC \\
\hline & 24 & & & em7 & GACTGCGTACGAATTATG \\
\hline & 25 & & & em8 & GACTGCGTACGAATTAGC \\
\hline
\end{tabular}

\section{Table A3}

EST-SSR primers and their sequence information.

\begin{tabular}{|c|c|c|c|c|}
\hline Primer Type & Name & Primer & Sequence $\left(5^{\prime}\right.$ to $\left.3^{\prime}\right)$ & Repeat Pattern \\
\hline \multirow[t]{12}{*}{ EST - SSR } & \multirow[t]{2}{*}{ OR09 } & Forward & TTGAAGCATTGTTGGAGGTAGATG & \multirow[t]{2}{*}{$(\text { TTTTTC })_{4}\left(\right.$ T $_{5}(\text { TTTTTC })_{1}$} \\
\hline & & Reverse & TCCCAACTAGGGAGAAATGTGC & \\
\hline & \multirow[t]{2}{*}{ OR12 } & Forward & GCCCCTGCAGTGACTCCTAC & \multirow{2}{*}{$(\mathrm{AG})_{7} \mathrm{G}(\mathrm{AG})_{3}$} \\
\hline & & Reverse & AAAAAGGCTTCGGACTCGATC & \\
\hline & \multirow[t]{2}{*}{ OR13 } & Forward & GAGAGAATCCAAGCCTCCGC & \multirow[t]{2}{*}{$(\mathrm{AAC})_{7} \mathrm{AGC}(\mathrm{AAC})_{1}$} \\
\hline & & Reverse & TGAAGGAGTCCGATGTTGACG & \\
\hline & \multirow[t]{2}{*}{ OR27 } & Forward & TCAGAAACAATGAAGGCCGC & \multirow[t]{2}{*}{$(\mathrm{CCT})_{6}$} \\
\hline & & Reverse & CCGTACAGGTCAAACACCGG & \\
\hline & \multirow[t]{2}{*}{ OR32 } & Forward & TCTTGCCAATTTATGCGTGTTC & \multirow[t]{2}{*}{$(\mathrm{AG})_{6} \mathrm{GG}(\mathrm{AG})_{2} \mathrm{GA}(\mathrm{AG})_{5} \mathrm{GG}(\mathrm{AG})_{1}$} \\
\hline & & Reverse & GAAACAAGCATCTTTTCCTGAATTC & \\
\hline & \multirow[t]{2}{*}{ OR40 } & Forward & GCCCAAGGACATCCAACTTG & \multirow[t]{2}{*}{$(\mathrm{GGT})_{4} \mathrm{GTT}(\mathrm{GGT})_{1}$} \\
\hline & & Reverse & CAACTGAACACСТСССАСАATG & \\
\hline
\end{tabular}

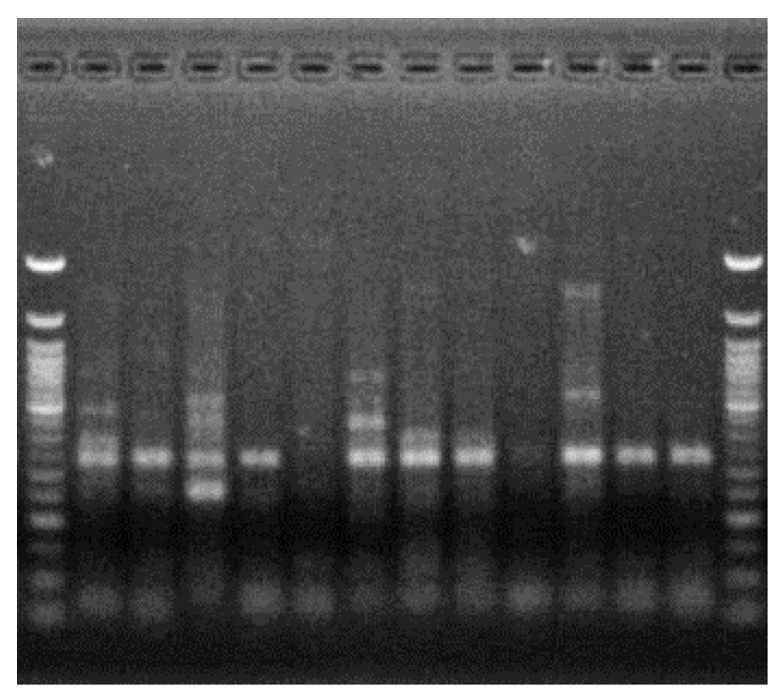

Fig. A1. Allelic pattern of SRAP marker combination, em4-me3, on an agarose gel image. 


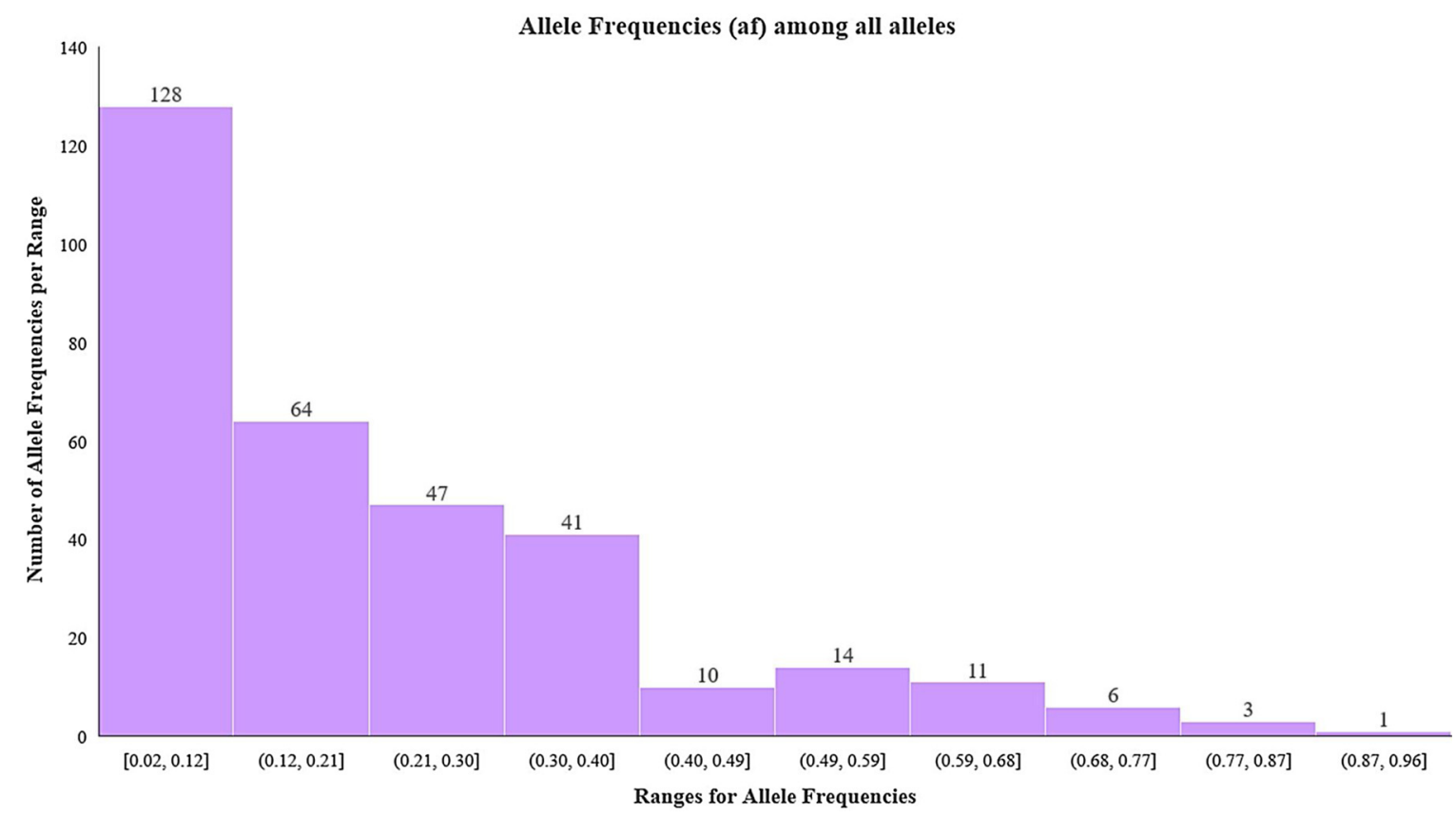

Fig. A2. Distribution of individual allele frequencies (af) among all alleles for both SRAP and EST-SSR markers.

Table A4

Gene flow in the eight sections of Origanum L. PhiPT values are shown below the diagonal. Values accepted as significant $(<0.15)$ are in bold characters indicating relatively low allelic differentiation between taxa. Number of migrants per generation $(\mathrm{Nm})$ for sections of Origanum $\mathrm{L}$. genera are shown above the diagonal and bold characters indicate relatively high gene flow between taxa $(P h i P T<0.15)$.

\begin{tabular}{|c|c|c|c|c|c|c|c|}
\hline$P h i P T$ values vs. $N m$ values & Amaracus & Anatolicon & Brevifilamentum & Chilocalyx & Majorana & Origanum & Prolaticorolla \\
\hline Amaracus & - & 2.97 & 1.91 & 1.09 & 0.98 & 0.81 & 0.68 \\
\hline Anatolicon & 0.08 & - & 6.08 & 1.67 & 1.34 & 0.82 & 0.62 \\
\hline Brevifilamentum & 0.12 & 0.04 & - & 3.48 & 1.64 & 1.51 & 1.17 \\
\hline Chilocalyx & 0.19 & 0.13 & 0.07 & - & 1.51 & 0.88 & 0.81 \\
\hline Majorana & 0.20 & 0.16 & 0.13 & 0.14 & - & 2.18 & 0.97 \\
\hline Origanum & 0.24 & 0.23 & 0.14 & 0.22 & 0.10 & - & 0.77 \\
\hline Prolaticorolla & 0.27 & 0.29 & 0.18 & 0.24 & 0.20 & 0.25 & - \\
\hline
\end{tabular}

Table A5

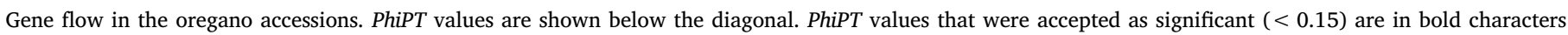

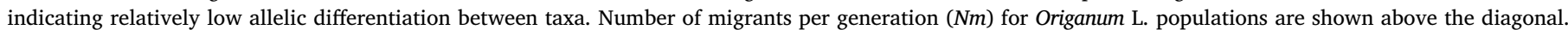
Bold characters indicate relatively high gene flow between taxa (PhiPT < 0.15).

\begin{tabular}{|c|c|c|c|c|c|c|c|c|c|c|c|}
\hline & OSA & $\mathrm{OHU}$ & OLE & ORO & OMA & OON & OSY & OVVU & $\mathrm{OVH}$ & OVVI & OLA \\
\hline OSA & - & 1.18 & 1.38 & 0.91 & 0.87 & 0.89 & 0.89 & 1.45 & 1.06 & 0.97 & 1.09 \\
\hline $\mathrm{OHU}$ & 0.18 & - & 1.16 & 0.56 & 0.6 & 0.67 & 0.64 & 0.91 & 0.64 & 0.79 & 0.87 \\
\hline OLE & 0.15 & 0.18 & - & 1.15 & 2.66 & 1.36 & 0.89 & 1.48 & 1.81 & 1.33 & 1.1 \\
\hline ORO & 0.22 & 0.31 & 0.18 & - & 0.62 & 0.64 & 0.65 & 0.73 & 0.58 & 0.65 & 0.67 \\
\hline OMA & 0.22 & 0.29 & 0.09 & 0.29 & - & 6.04 & 0.72 & 0.91 & 0.96 & 1.51 & 1.03 \\
\hline OON & 0.22 & 0.27 & 0.16 & 0.28 & 0.04 & - & 0.81 & 1.23 & 1.33 & 2.43 & 1.09 \\
\hline OSY & 0.22 & 0.28 & 0.22 & 0.28 & 0.26 & 0.24 & - & 3.27 & 0.89 & 0.92 & 0.84 \\
\hline OVVU & 0.15 & 0.22 & 0.14 & 0.26 & 0.22 & 0.17 & 0.07 & - & 3.07 & 2.17 & 1.52 \\
\hline $\mathrm{OVH}$ & 0.19 & 0.28 & 0.12 & 0.30 & 0.21 & 0.16 & 0.22 & 0.08 & - & 3.06 & 0.98 \\
\hline OVVI & 0.20 & 0.24 & 0.16 & 0.28 & 0.14 & 0.09 & 0.21 & 0.10 & 0.08 & - & 1.29 \\
\hline OLA & 0.19 & 0.22 & 0.19 & 0.27 & 0.19 & 0.19 & 0.23 & 0.14 & 0.20 & 0.16 & - \\
\hline
\end{tabular}


Table A6

Subpopulations and admixed individuals as determined by population structure analysis at $K=8$ and $K=3$.

\begin{tabular}{|c|c|c|c|c|c|c|c|}
\hline \multicolumn{4}{|l|}{$K=8$} & \multicolumn{4}{|l|}{$K=3$} \\
\hline Individual & $\begin{array}{l}\text { Inferred } \\
\text { Ancestry }\end{array}$ & $\begin{array}{l}\text { Significance } \\
\text { Value }\end{array}$ & Section & Individual & $\begin{array}{l}\text { Inferred } \\
\text { Ancestry }\end{array}$ & $\begin{array}{l}\text { Significance } \\
\text { Value }\end{array}$ & Section \\
\hline OSO1 & Admixed & 0.60 & Amaracus, Anatolicon, & OBO1 & Admixed & 0.52 & Amaracus, Anatolicon, \\
\hline OHYI & Admixed & 0.62 & Brevifilamentum, & OSO1 & Admixed & 0.60 & Brevifilamentum, \\
\hline OSI1 & Admixed & 0.33 & Majorana, and Origanum & $O H Y 1$ & Admixed & 0.62 & Chilocalyx Majorana, and \\
\hline OBA1 & Admixed & 0.51 & & OSII & Admixed & 0.43 & Origanum \\
\hline OON1 & Admixed & 0.66 & & OBA1 & Admixed & 0.57 & \\
\hline OVVU1 & Admixed & 0.66 & & OHU1 & Admixed & 0.59 & \\
\hline OVVU2 & Admixed & 0.69 & & OHU2 & Admixed & 0.58 & \\
\hline$O V G 1$ & Admixed & 0.70 & & OBI1 & Admixed & 0.60 & \\
\hline OVVI1 & Admixed & 0.65 & & OVO1 & Admixed & 0.59 & \\
\hline OVVI2 & Admixed & 0.53 & & OMA1 & Admixed & 0.62 & \\
\hline OAC1 & SP I & 0.97 & Brevifilamentum and & OSY3 & Admixed & 0.54 & \\
\hline OHA1 & SP I & 0.94 & Chilocalyx & $O V G 1$ & Admixed & 0.63 & \\
\hline OLE2 & SP I & 0.75 & & $\mathrm{OACl}$ & SP I & 0.97 & Brevifilamentum and \\
\hline OMU1 & SP I & 0.91 & & OHA 1 & SP I & 0.92 & Chilocalyx \\
\hline OMI1 & SP I & 0.96 & & OLE2 & SP I & 0.89 & \\
\hline OSY1 & SP II & 0.96 & Majorana & OMU1 & SP I & 0.94 & \\
\hline OSY2 & SP II & 0.96 & & ORO1 & SP I & 0.87 & \\
\hline OSY3 & SP II & 0.94 & & $\mathrm{ORO} 2$ & SP I & 0.97 & \\
\hline OBO1 & SP III & 0.73 & Amaracus, & OMI1 & SP I & 0.96 & \\
\hline OLE1 & SP III & 0.93 & Brevifilamentum, & OSA1 & SP II & 0.91 & Amaracus \\
\hline OAM1 & SP III & 0.94 & Longitubus, Chilocalyx, & OSA2 & SP II & 0.87 & \\
\hline OBI1 & SP III & 0.75 & and Majorana & OSA3 & SP II & 0.78 & \\
\hline OVO1 & SP III & 0.92 & & OSA4 & SP II & 0.92 & \\
\hline OMA1 & SP III & 0.78 & & OSA5 & SP II & 0.94 & \\
\hline OMA2 & SP III & 0.86 & & OSA6 & SP II & 0.90 & \\
\hline OON2 & SP III & 0.80 & & OSA7 & SP II & 0.99 & \\
\hline ORO1 & SP IV & 0.92 & Brevifilamentum & OSA8 & SP II & 0.96 & \\
\hline $\mathrm{ORO} 2$ & SP IV & 0.98 & & OLE1 & SP III & 0.79 & Brevifilamentum, \\
\hline OSA1 & SP V & 0.93 & Amaracus & OAM1 & SP III & 0.85 & Longitubus, Majorana, \\
\hline OSA2 & SP V & 0.90 & & OMA2 & SP III & 0.86 & Origanum, and \\
\hline OSA3 & SP V & 0.70 & & OON1 & SP III & 0.84 & Prolaticorolla \\
\hline OSA4 & SP V & 0.95 & & OON2 & SP III & 0.80 & \\
\hline OSA5 & SP V & 0.94 & & OSY1 & SP III & 0.80 & \\
\hline OSA6 & SP V & 0.95 & & OSY2 & SP III & 0.92 & \\
\hline OSA7 & SP V & 0.99 & & OVVU1 & SP III & 0.98 & \\
\hline OSA8 & SP V & 0.97 & & OVVU2 & SP III & 0.92 & \\
\hline OHU1 & SP VI & 0.94 & Brevifilamentum & OVH1 & SP III & 0.98 & \\
\hline OHU2 & SP VI & 0.94 & & OVH2 & SP III & 0.98 & \\
\hline OVH1 & SP VII & 0.95 & Origanum & OVVI1 & SP III & 0.89 & \\
\hline OVH2 & SP VII & 0.96 & & OVVI2 & SP III & 0.96 & \\
\hline OLA1 & SP VIII & 0.84 & Prolaticorolla & OLA1 & SP III & 0.75 & \\
\hline OLA2 & SP VIII & 0.95 & & OLA2 & SP III & 0.92 & \\
\hline OLA3 & SP VIII & 0.92 & & OLA3 & SP III & 0.78 & \\
\hline OLA4 & SP VIII & 0.98 & & OLA4 & SP III & 0.96 & \\
\hline OLA5 & SP VIII & 0.93 & & OLA5 & SP III & 0.97 & \\
\hline OLA6 & SP VIII & 0.77 & & OLA6 & SP III & 0.95 & \\
\hline
\end{tabular}

Definitions are as follows: Individual codes with italic font indicate the observed admixed individuals for $K=3$ and $K=8$; SP $=$ Sub population. 

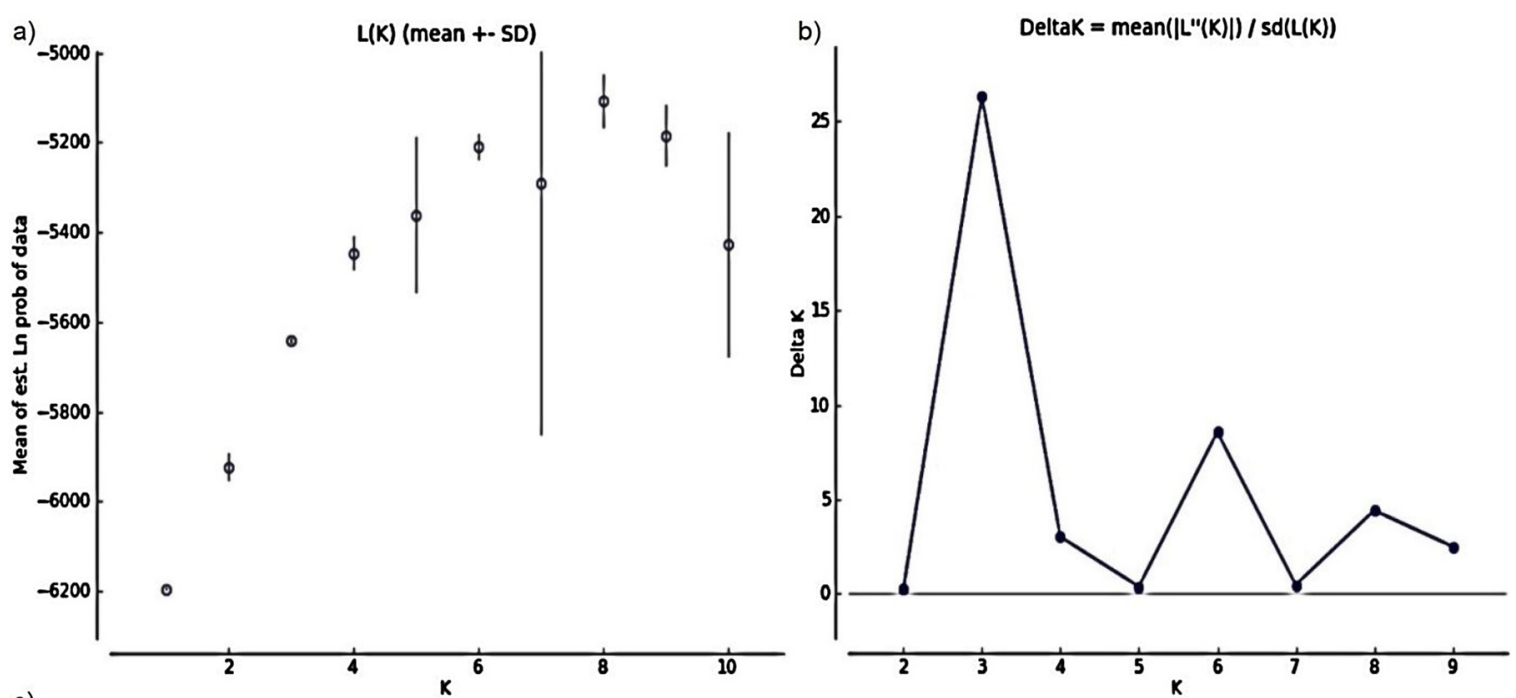

c)

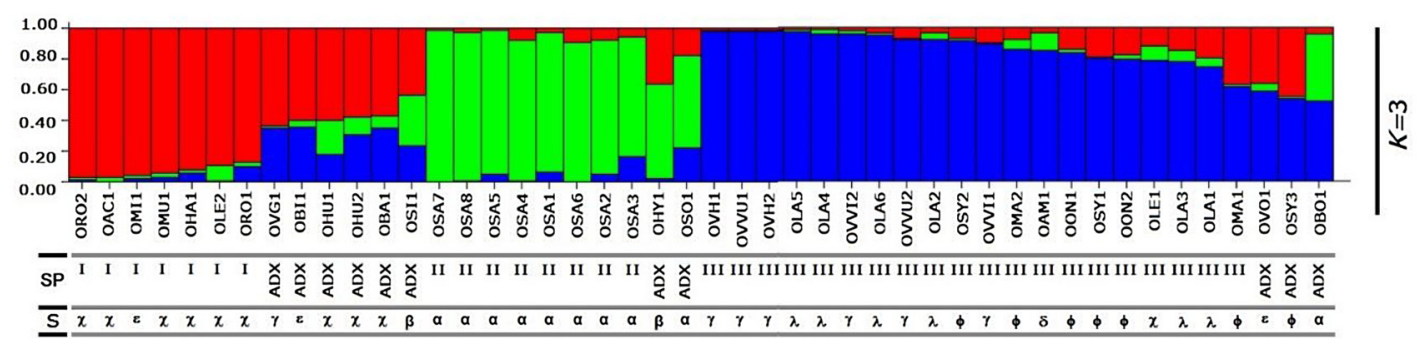

Fig. A3. (a) Likelihood values from Structure Harvester analysis are plotted for the ten different subpopulations tested in the analysis. (b) Delta $K$ is plotted for each $K$ with peaks indicating a high probability that the number of subpopulations was $K=3$ or $K=8$. (c) Structure graph for $K=3$.

Table A7

The results for Bayesian clustering for $K=8$ and $K=3$.

\begin{tabular}{|c|c|c|c|c|}
\hline Sub population & Ns & $\Sigma N i$ & $\mathrm{He}$ & $F_{S T}$ values \\
\hline \multicolumn{5}{|l|}{$K=8$} \\
\hline SP I & 2 & 5 & 0.34 & 0.02 \\
\hline SP II & 1 & 3 & 0.15 & 0.65 \\
\hline SP III & 4 & 8 & 0.23 & 0.32 \\
\hline SP IV & 1 & 2 & 0.24 & 0.49 \\
\hline SP V & 1 & 8 & 0.22 & 0.39 \\
\hline SP VI & 1 & 2 & 0.16 & 0.66 \\
\hline SP VII & 1 & 2 & 0.09 & 0.8 \\
\hline SP VIII & 1 & 6 & 0.15 & 0.58 \\
\hline Admixed & 4 & 10 & & \\
\hline \multicolumn{5}{|l|}{$K=3$} \\
\hline SP I & 2 & 7 & 0.36 & 0.0008 \\
\hline SP II & 1 & 8 & 0.21 & 0.42 \\
\hline SP III & 5 & 19 & 0.21 & 0.39 \\
\hline Admixed & 5 & 12 & & \\
\hline
\end{tabular}

Notations are as follows: $\mathrm{SP}=\mathrm{Sub}$ population; $\mathrm{Ns}=$ Number of sections for that cluster; $\Sigma N i=$ Total number of individuals; $\mathrm{He}=$ Expected heterozygosity; $F_{S T}=$ Fixation index.

\section{References}

Aboukhalid, K., Machon, N., Lambourdière, J., Abdelkrim, J., Bakha, M., Douaik, A. et al., 2017. Analysis of genetic diversity and population structure of the endangered Origanum compactum from Morocco, using SSR markers: implication for conservation. Biol. Conserv. 212, 172-182.

Abuzayed, M., El-Dabba, N., Frary, A., Doganlar, S., 2016. GDdom: an online tool for calculation of dominant marker gene diversity. Biochem. Genet. 55, 155-157. https://doi.org/10.1007/s10528-016-9779-0.

Ayanoglu, F., Ergul, A., Arsan, M., 2006. Assessment of genetic diversity in Turkish Oregano (Origanum onites L.) germplasm by AFLP analysis. J. Hortic. Sci. Biotechnol. $81,45-50$.

Costa, C.M., Roberts, R.P., 2014. Techniques for improving the quality and quantity of DNA extracted from herbarium specimens. Phytoneuron. 48, 1-8.

Doyle, J.J., Doyle, J.L., 1987. CTAB DNA extraction in plants. Phytochem. Bull. 19, $11-15$.
Duman, H., Aytac, Z., Ekici, M., Karaveliogullari, F.A., Donmez, A., Duran, A., 1995. Three new species (Labiatae) from Turkey. Flora Mediterr. 5, 221-228 ISSN: 11204052.

Earl, D.A., vonHoldt, B.M., 2012. STRUCTURE HARVESTER: a website and program for visualizing STRUCTURE output and implementing the Evanno Method. Conserv. Genet. Resour. 4, 359-361. https://doi.org/10.1007/s12686-011-9548-7.

Efe, M., 2013. Türkiye'de yetişen Origanum L. (Labiatae) türlerinin gövde ve yaprak anatomisi. Master Thesis. Inonu University, Malatya. http://ulusaltezmerkezi.com/ turkiyede-yetsisen-origanum-1-labiatae-turlerinin-govde-ve-yaprak-anatomisi/10/.

Frankham, R., Briscoe, D.A., Ballou, J.D., 2002. Introduction to Conservation Genetics. Cambridge University Press, Cambridge, United Kingdom, UK.

Gurbuz, B., Ipek, A., Ayvaz, N., 2011. Türkiye florasındaki Origanum türlerinin yayılıș alanları ve ticareti. Türk Bilimsel Derlemeler Derg. 4, 55-58 ISSN: 1308-0040, EISSN: 2146-0132.

Guzelmansur, A., Lise, Y., 2013. Amanos Dağları'nın biyoçeşitliliği. MKU Ziraat Fakülttesi Derg. 18, 55-68 ISSN: 1300-9362.

Ietswaart, J.H., 1980. A Taxonomic Revision of the Genus Origanum (Labiatae) 4. Leiden 
University Press, The Hague, pp. 153 PhD Thesis.

Ince, A.G., Karaca, M., Elmasulu, S.Y., 2014. New microsatellite and CAPS-microsatellite markers for clarifying taxonomic and phylogenetic relationships within Origanum L. Mol. Breed. 34, 643-654.

Karaca, M., Ince, A.G., Aydın, A., Ay, S., 2013. Cross-genera transferable e-microsatellite markers for 12 genera of the Lamiaceae family. J. Sci. Food Agric. 93, 1869-1879.

Katsiotis, A., Nikoloudakis, N., Linos, A., Drossou, A., Constantinidis, T., 2009. Phylogenetic relationships in Origanum spp. based on rDNA sequences and intra-genetic variation of Greek O. vulgare subsp. hirtum revealed by RAPD. Sci. Hortic. 121, 103-108.

Kaufmann, M., Wink, M., 1994. Molecular systematics of the Nepetoideae (family Labiatae): phylogenetic implications from rbcL gene sequences. Z. Naturforsch. C. Biosci. 49, 635-645.

Kitiki, A., Kesercioglu, T., Tan, A., Nakiboglu, M., Otan, H., Sari, A.O., 1997. Ege ve Bat1 Akdeniz Bölgelerinde yayılış gösteren bazı Origanum L. türlerinde biyosistematik araștırmalar. J. Aegean Agric. Res. Instit. 7, 26-40.

Li, G., Quiros, C.F., 2001. Sequence-related Amplified Polymorphism (SRAP), a new marker system based on a simple PCR reaction: its application to mapping and gene tagging in Brassica. TAG Theor. Appl. Genet. 103, 455-461.

Loveless, M.D., Hamrick, J.L., 1984. Ecological determinants of genetic structure in plant populations. Annu. Rev. Ecol. Evol. Syst. 15, 65-95.

Lukas, B., Samuel, R., Mader, E., Baser, K.H.C., Duman, H., Novak, J., 2013. Complex evolutionary relationships in Origanum section Majorana (lamiaceae). Bot. J. Linn. Soc. 171, 667-686. https://doi.org/10.1111/boj.12022.

Marieschi, M., Torelli, A., Poli, F., Bianchi, A., Bruni, R., 2010. Quality control of commercial mediterranean Oregano: development of SCAR markers for the detection of the adulterants Cistus incanus L., Rubus caesius L. and Rhus coriaria L. Food Control. 21, 998-1003.

Mechergui, K., Jaouadi, W., Bekele, W.A., Khouja, M.L., Friedt, W., 2017. Genetic structure and differentiation among Oregano [Origanum vulgare subsp. glandulosum (Desf.) Ietswaart] provenances from North Africa: bioinformatic approaches cause systematic bias. Genet. Resour. Crop. Evol. 64, 717-732.

Novak, J., Lukas, B., Bolzer, K., Grausgruber-Gröger, S., Degenhardt, J., 2008. Identification and characterization of simple sequence repeat markers from a glandular Origanum vulgare expressed sequence tag. Mol. Ecol. Resour. 8, 599-601.
Peakall, R., Smouse, P.E., 2006. GENALEX 6: genetic analysis in excel. Population genetic software for teaching and research. Mol. Ecol. Notes 6, 288-295.

Peakall, R., Smouse, P.E., 2012. GenAlEx 6.5: genetic analysis in excel. Population genetic software for teaching and research—an update. Bioinformatics 28, 2537-2539.

Perrier, X., Jacquemoud-Collet, J.P., 2006. DARwin Software: Dissimilarity Analysis and Representation for Windows. Accessed from. , Accessed in 23.11.2016, 5 pm. http://darwin.cirad.fr/darwin.

Polat, R., Satıl, F., 2012. An ethnobotanical survey of medicinal plants in Edremit gulf (Balıkesir - Turkey). J. Ethnopharm. 139, 626-641.

Pritchard, J.K., Stephens, M., Donnelly, P., 2000. Inference of population structure using multilocus genotype data. Genetics 155, 945-959.

Sadikoglu, N., 2012. Türkiye Bitkileri listesi (Damarlı Bitkiler; Origanum). Nezahat Gökyiğit Botanik Bahcesi ve Flora araștırmaları Derneği Yayını 568-570.

Sadikoglu, N., Ozhatay, N., 2015. Morphological characteristics of exported taxa as Oregano from Turkey I: Origanum. J. Fac. Pharm. Istanbul Univ. 45, 87-126.

Sari, A.O., Altunkaya, M., 2015. Doğadan tarlaya... Kekik. Türkiye Tohumcular Birliğ Derg 15, 22-27.

Scutari, M., Denis, J.B., 2014. Bayesian Networks: With Examples in R. CRC Press, Florida, United States of America.

Stanev, S., Zagorcheva, T., Atanassov, I., 2016. Lavender cultivation in Bulgaria-21st century developments, breeding challenges and opportunities. Bulg. J. Agric. Sci. 22, 584-590.

Tepe, B., Cakır, A., Tepe, A.S., 2016. Medicinal uses, phytochemistry, and pharmacology of Origanum onites (L.): a review. Chem. Biodivers. 13, 504-520. https://doi.org/10 1002/cbdv.201500069.

Van Looy, K., Jacquemyn, H., Breyne, P., Honnay, O., 2009. Effects of flood events on the genetic structure of Riparian populations of the grassland plant Origanum vulgare. Biol. Conserv. 142, 870-878.

Wood, A.R., Gardner, J.P., 2007. Small spatial scale population genetic structure in two Limpet species endemic to the Kermadec Islands, New Zealand. Mar. Ecol. Prog. Ser. 349, 159-170.

World Checklist of Selected Plant Families, 2017. Facilitated by the Royal Botanic Gardens, Kew. Accessed from. , Accessed in August 2 2017, 11 pm. http://apps. kew.org/wcsp/. 